Article

\title{
Isoxazolidine Conjugates of N3-Substituted 6-Bromoquinazolinones-Synthesis, Anti-Varizella-Zoster Virus, and Anti-Cytomegalovirus Activity
}

\author{
Magdalena Grabkowska-Drużyc ${ }^{1}$, Graciela Andrei ${ }^{2}$, Dominique Schols ${ }^{2}$, Robert Snoeck ${ }^{2}$ and \\ Dorota G. Piotrowska ${ }^{1, *}$ \\ 1 Bioorganic Chemistry Laboratory, Faculty of Pharmacy, Medical University of Lodz, Muszyńskiego 1, \\ 90-151 Lodz, Poland; magdalena.grabkowska-druzyc@umed.lodz.pl \\ 2 Rega Institute for Medical Research, KU Leuven, Herestraat 49, B-3000 Leuven, Belgium; \\ Graciela.Andrei@rega.kleuven.be (G.A.); Dominique.Schols@rega.kleuven.be (D.S.); \\ Robert.Snoeck@rega.kleuven.be (R.S.) \\ * Correspondence: dorota.piotrowska@umed.lodz.pl; Tel.: +48-42-677-92-33; Fax: +48-42-678-83-98
}

Received: 29 June 2018; Accepted: 27 July 2018; Published: 28 July 2018

\begin{abstract}
Dipolar cycloaddition of $N$-methyl C-(diethoxyphosphoryl) nitrone to N3-substituted 6-bromo-2-vinyl-3H-quinazolin-4-ones gave (3-diethoxyphosphoryl) isoxazolidines substituted at $\mathrm{C} 5$ with quinazolinones modified at N3. All isoxazolidine cycloadducts were screened for antiviral activity against a broad spectrum of DNA and RNA viruses. Several isoxazolidines inhibited the replication of both thymidine kinase wild-type and deficient $\left(\mathrm{TK}^{+}\right.$and $\left.\mathrm{TK}^{-}\right)$varicella-zoster virus strains at $\mathrm{EC}_{50}$ in the 5.4-13.6 $\mu \mathrm{M}$ range, as well as human cytomegalovirus $\left(\mathrm{EC}_{50}=8.9-12.5 \mu \mathrm{M}\right)$. Isoxazolidines trans-11b, trans-11c, trans-11e, trans-11f/cis-11f, trans-11g, trans-11h, and trans-11i/cis-11i exhibited moderate cytostatic activity towards the human lymphocyte cell line CEM $\left(\mathrm{IC}_{50}=9.6-17 \mu \mathrm{M}\right)$.
\end{abstract}

Keywords: phosphonate; isoxazolidine; quinazolinones; antiviral; cytostatic

\section{Introduction}

Herpesviruses are enveloped, icosahedral viruses containing double-stranded DNA. What fundamentally distinguishes herpesviruses from others is the ability to establish latent infection and reactivating when the host immune system is impaired. Human cytomegalovirus (HCMV) and varicella zoster virus (VZV) belong to the family of herpesviruses which cause infections usually acquired in childhood [1-3]. For the treatment of viral infections caused by herpesviruses, including VZV and HCMV, several drugs, such as acyclovir (e.g., Zovirax), valacyclovir (e.g., Valtrex), famciclovir (e.g., Famvir), brivudin (e.g., Zostex, Helpin), and ganciclovir (e.g., Cymevene), have been used [3-5].

Despite the wide range of available drugs, effective treatment of viral infections is still limited. This is mainly due to the specificity of viral infections and the ability of viruses to mutate, which is associated with the acquisition of drug resistance. Therefore, new compounds with potential biological activity are being sought all the time. Quinazolinone and its derivatives have been extensively studied because of their wide range of biological activities, including antiviral [6], anticancer [7,8], antifungal [9], antibacterial [10,11], antitubercular [12,13], anti-inflammatory [11,14], anticonvulsant [15], hypolipidemic [16], analgesic [17], or immunotropic properties [18].

The antiviral activity of compounds containing the C6-substituted quinazolin-4-one framework has been discovered in recent years (Figure 1). For example, 5-bromo-2-(6-bromo4-oxo-2-phenyl-4H-quinazolin-3-yl)-benzoic acid $\mathbf{1}$ was reported to possess distinct antiviral activity against 
both herpes simplex viruses 1 and 2 (HSV-1 and HSV-2) and vaccinia virus (VACV) (EC $50=12 \mu \mathrm{g} / \mathrm{mL}$ ) [19], whereas compound 2 exhibited activity against vaccinia virus in $\mathrm{E}_{6} \mathrm{SM}$ cell cultures (MIC of $1.92 \mu \mathrm{g} / \mathrm{mL}$ ) [20]. Another analogue, i.e., 2-methyl-3-(substituted-benzalamino)-4(3H)-quinazolinone 3 , was found to exhibit antiviral activity against tobacco mosaic virus (TMV) in vivo. Compound 3 showed curative effects of $54 \%$, which was slightly higher than that of a reference drug, Ningnanmycin [21]. Very recently quinazolin-4(3H)-ones 4-6 were synthesized and evaluated for inhibitory action on the replication of influenza A virus $\left(\mathrm{H}_{5} \mathrm{~N}_{1}\right)$, as well as to test toxicity on in vitro cell lines. In general, quinazolin-4(3H)-ones containing a chalcone skeleton $\mathbf{4}$, thiosemicarbazone 5, and hydrazide 6 showed moderate antiviral activity against $\mathrm{H}_{5} \mathrm{~N}_{1}$ (inhibition rate: $38 \%, 47 \%, 25 \%$, respectively, for $4,5,6$ ) compared to a reference drug, Zanamivir [22]. In addition, compounds 7 and 8 possessing a nitro group at $\mathrm{C} 6$ were reported as potent inhibitors of Venezuelan Equine Encephalitis Virus (VEEV) $\left(\mathrm{EC}_{50}=0.8 \mu \mathrm{M}, \mathrm{CC}_{50}=50 \mu \mathrm{M}\right)$ [23]. Quinazolinone (aS)-9 displayed high selectivity for PI4KIII $\alpha$ and appeared to be potent inhibitors of hepatitis $C$ virus $(\mathrm{HCV})$ replication in vitro. Moreover, compound (aS)-9 exhibited higher potency for PI4KIII $\alpha$ than its atropisomer $a R$ ( $\mathrm{pIC}_{50}$ of 8.3 vs. 6.9$)$ and an improved selectivity range (2.7-3.2 vs. 1.4-2.1) against the other lipid kinases [24].

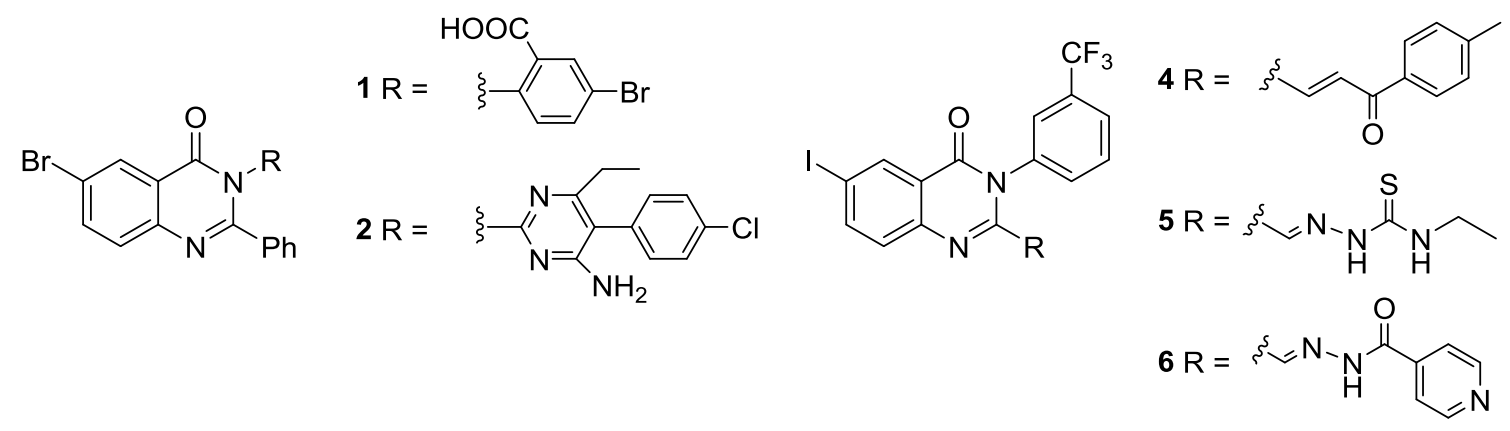<smiles>Cc1nc2ccc(Br)cc2c(=O)n1/N=C/c1ccccc1C(F)(F)F</smiles>

3<smiles>COc1ncc(-c2ccc3nc(N)n(-c4ccccc4C(F)(F)F)c(=O)c3c2)cc1S(=O)(=O)Nc1ccc(F)cc1F</smiles>

(aS)-9<smiles>[R]N1CCN(Cc2nc3ccc([N+](=O)[O-])cc3c(=O)n2-c2ccccc2F)CC1</smiles>

$7 \mathrm{R}=\mathrm{Me}$

$8 \mathrm{R}=\mathrm{Et}$

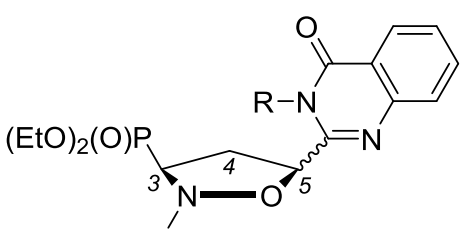

10

Figure 1. Examples of C6-substituted quinazolinone derivatives with antiviral activity.

Recently, we have succeeded in synthesis of a series of quinazolinones substituted at C3 with a (diethoxyphosphoryl)isoxazolidine moiety 10. Several of the synthesized analogues exhibited moderate activity against varicella zoster virus (VZV) and human cytomegalovirus (HCMV) [25]. On the basis of these observations, and in continuation of our search for new biologically active compounds [25], a novel series of quinazolinone derivatives of general formula $\mathbf{1 1}$ having an isoxazolidine ring at $\mathrm{C} 2$, different substituents at N3, and an additional bromine atom at $\mathrm{C} 6$ was 
synthesized. The synthetic strategy for our new isoxazolidine-conjugates of quinazolinones relies on the 1,3-dipolar cycloaddition of N-methyl-C-(diethoxyphosphoryl)nitrone 12 [26] with selected 6-bromo-2-vinyl-3H-quinazolin-4-ones 13 (Scheme 1).

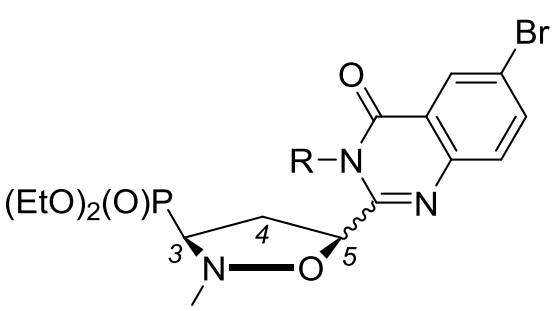

11

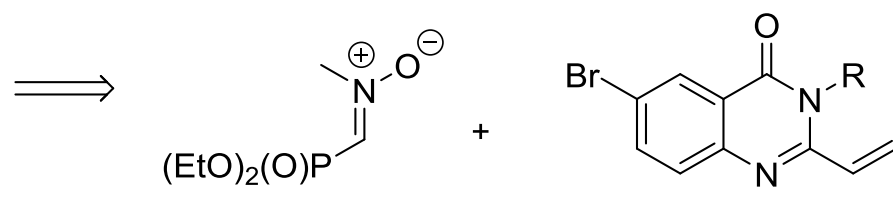

12

13

Scheme 1. Retrosynthesis of isoxazolidine conjugates of 6-bromoquinazolinones.

\section{Results and Discussion}

\subsection{Chemistry}

The respective 3-substituted 6-bromo-2-vinyl-3H-quinazolin-4-ones 13a-k were synthesized starting from the commercially available isatoic acid anhydride, which was first reacted with bromine and then transformed into 5-bromoanthranilic acid amide $\mathbf{1 4}$ according to the procedure in the literature $[27,28]$. Reaction 5-bromoanthranilic acid amide $\mathbf{1 4}$ with 3-chloropropionyl chloride followed by cyclization and dehydrohalogenation led to the formation of 6-bromo-2-vinyl-3H-quinazolin-4-one $13 \mathbf{a}$, which was then used as a key intermediate in the preparation of N3-substituted derivatives 13b-13k via alkylation with the respective benzyl bromides, as well as with methyl or ethyl iodide [29] (Scheme 2).

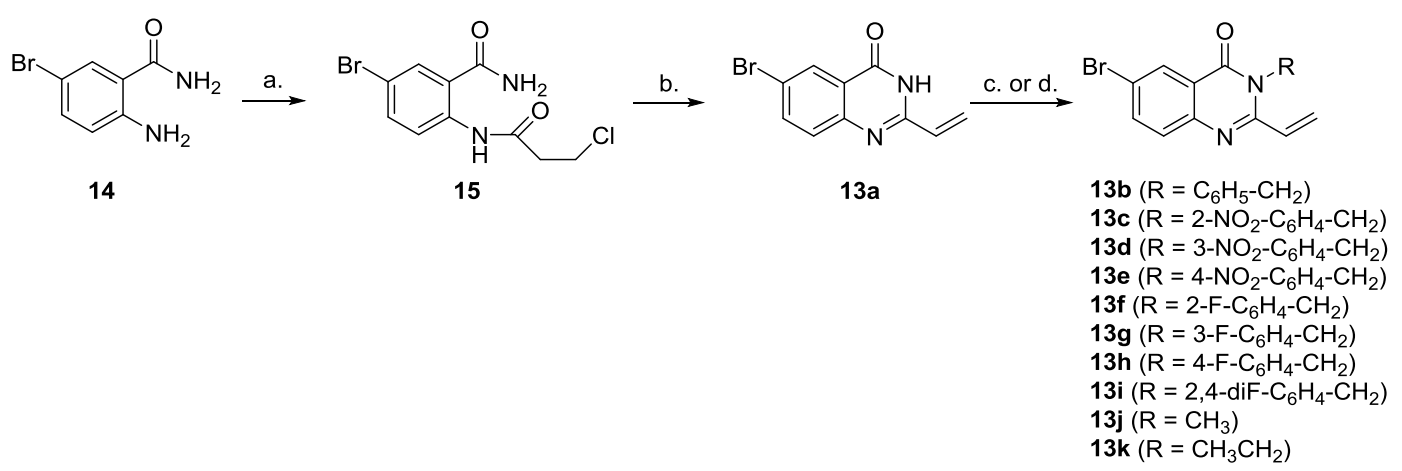

Scheme 2. Synthesis of 3-substituted 6-bromo-2-vinylquinazolinones 13a-13k. Reaction and conditions: a. 3-chloropropionyl chloride, 1,4-dioxane, $0{ }^{\circ} \mathrm{C}$; b. 5\% NaOH-EtOH (2:1); c. $\mathrm{RBr}, \mathrm{KOH}, 105{ }^{\circ} \mathrm{C}$; d. $\mathrm{MeI}$ or EtI, $\mathrm{KOH}, \mathrm{CH}_{3} \mathrm{CN}, 60^{\circ} \mathrm{C}$.

The 1,3-dipolar cycloadditions of nitrone $\mathbf{1 2}$ with the respective 6-bromo-2-vinylquinazolinones 13a-13k were carried out at $70{ }^{\circ} \mathrm{C}$ in toluene and afforded mixtures of diastereoisomeric isoxazolidines trans-11a-11k and cis-11a-11k (Scheme 3, Table 1). Ratios of trans/cis diastereoisomers were determined on the basis of the ${ }^{31} \mathrm{P}-\mathrm{NMR}$ spectra of crude products and confirmed by the analysis of ${ }^{1} \mathrm{H}-\mathrm{NMR}$ spectra data. In all cases good trans/cis diastereoselectivities were observed (in the range of 76-88\%) and trans-isomers predominated. The mixtures of isoxazolidine cycloadducts were separated chromatographically on silica gel. The isolation of pure isomers was successfully accomplished for the major isomers trans-11a $(\mathrm{R}=\mathrm{H})$, trans- $11 \mathrm{~b}\left(\mathrm{R}=\mathrm{C}_{6} \mathrm{H}_{5} \mathrm{CH}_{2}\right)$, trans-11c $\left(\mathrm{R}=2-\mathrm{NO}_{2}-\mathrm{C}_{6} \mathrm{H}_{4}-\mathrm{CH}_{2}\right)$, trans- $11 \mathrm{~d}\left(\mathrm{R}=3-\mathrm{NO}_{2}-\mathrm{C}_{6} \mathrm{H}_{4}-\mathrm{CH}_{2}\right)$, trans-11e $\left(\mathrm{R}=4-\mathrm{NO}_{2}-\mathrm{C}_{6} \mathrm{H}_{4}-\mathrm{CH}_{2}\right)$, trans-11g $\left(\mathrm{R}=3-\mathrm{F}-\mathrm{C}_{6} \mathrm{H}_{4}-\mathrm{CH}_{2}\right)$, trans-11h $\left(\mathrm{R}=4-\mathrm{F}_{-} \mathrm{C}_{6} \mathrm{H}_{4}-\mathrm{CH}_{2}\right)$, trans-11j $\left(\mathrm{R}=\mathrm{CH}_{3}\right)$, and trans-11k $\left(\mathrm{R}=\mathrm{CH}_{3} \mathrm{CH}_{2}\right)$, as well as for a minor isomer cis-11a $(\mathrm{R}=\mathrm{H})$. 


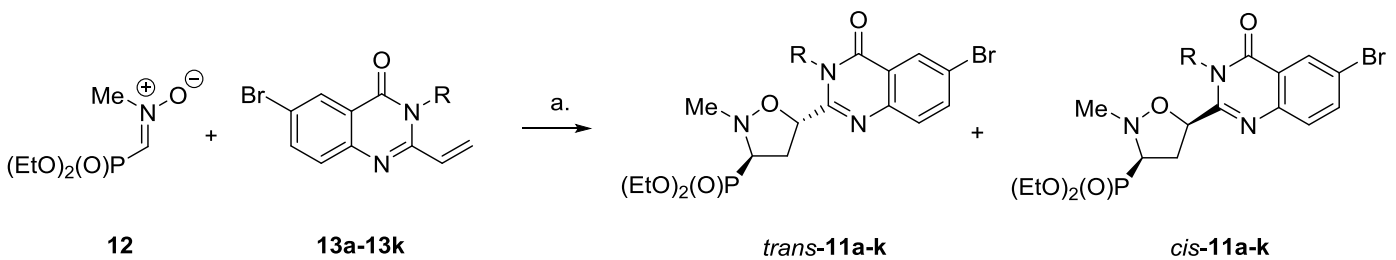

Scheme 3. Synthesis of isoxazolidines trans-11a-k and cis-11a-k. Reaction and conditions: a. toluene, $70{ }^{\circ} \mathrm{C}, 24 \mathrm{~h}$.

Table 1. Isoxazolidines trans-11 and cis-11 obtained according to Scheme 3.

\begin{tabular}{|c|c|c|c|}
\hline \multirow{2}{*}{ Entry } & Quinazolinone 13 & \multirow{2}{*}{ Ratio of trans-11:cis-11 } & \multirow{2}{*}{ Yield (\%) } \\
\hline & $\mathbf{R}$ & & \\
\hline a & $\mathrm{H}$ & $92: 8$ & trans-11a $(23)^{a}+c^{2}-11 a(5)^{a}+$ trans-11a and cis-11a $(62)^{b}$ \\
\hline b & $\mathrm{C}_{6} \mathrm{H}_{5}-\mathrm{CH}_{2}$ & $92: 8$ & trans-11b $(8)^{a}+$ trans $-\mathbf{1 1} \mathbf{b}$ and cis-11 $\mathbf{b}(83)^{b}$ \\
\hline c & $2-\mathrm{NO}_{2}-\mathrm{C}_{6} \mathrm{H}_{4}-\mathrm{CH}_{2}$ & $94: 6$ & trans $-11 \mathrm{c}(30)^{\mathrm{a}}+$ trans $-11 \mathrm{c}$ and cis-11c $(62) \mathrm{b}$ \\
\hline d & $3-\mathrm{NO}_{2}-\mathrm{C}_{6} \mathrm{H}_{4}-\mathrm{CH}_{2}$ & $92: 8$ & trans-11d $(14)^{a}+$ trans $-11 d$ and cis-11d $(80)^{b}$ \\
\hline e & $4-\mathrm{NO}_{2}-\mathrm{C}_{6} \mathrm{H}_{4}-\mathrm{CH}_{2}$ & $90: 10$ & 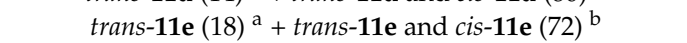 \\
\hline f & $2-\mathrm{F}-\mathrm{C}_{6} \mathrm{H}_{4}-\mathrm{CH}_{2}$ & 90:10 & trans-11f and cis-11f $(96)^{\mathrm{b}}$ \\
\hline g & $3-\mathrm{F}-\mathrm{C}_{6} \mathrm{H}_{4}-\mathrm{CH}_{2}$ & $92: 8$ & 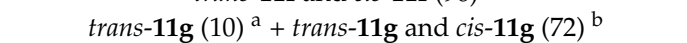 \\
\hline h & $4-\mathrm{F}-\mathrm{C}_{6} \mathrm{H}_{4}-\mathrm{CH}_{2}$ & $92: 8$ & 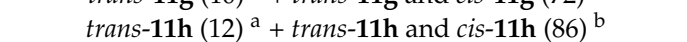 \\
\hline i & $2,4-\mathrm{diF}-\mathrm{C}_{6} \mathrm{H}_{3}-\mathrm{CH}_{2}$ & 93:7 & ${\text { trans-11i and cis-11i }(82)^{\mathrm{b}}}^{\mathrm{b}}$ \\
\hline j & $\mathrm{CH}_{3}$ & $94: 6$ & 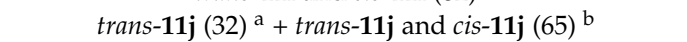 \\
\hline k & $\mathrm{CH}_{3} \mathrm{CH}_{2}$ & $88: 12$ & trans-11k $(14)^{a}+$ trans $-\mathbf{1 1} \mathbf{k}$ and cis-11k (80) ${ }^{b}$ \\
\hline
\end{tabular}

Stereochemistry of the cycloaddition of a nitrone 12 to N3-substituted derivatives of 2-vinyl-3H-quinazolin-4-ones has recently been described and relative configurations of transand cis-isoxazolidine cycloadducts were established based on conformational analysis [25]. Since the introduction of the bromine atom at C6 of the quinazolin-4-one framework has no influence on the stereochemical outcome of the reaction of nitrone $\mathbf{1 2}$ with N3-susbstituted 2-vinyl-3H-quinazolin-4-ones, the trans and cis configurations of the major trans-11a-k and minor cis-11a-k isomers were assigned taking advantage of our previous observations.

\subsection{Antiviral and Cytostatic Evaluation}

\subsubsection{Antiviral Activity}

Pure isomers trans-11a, trans-11b, trans-11c, trans-11d, trans-11e, trans-11g, trans-11h, trans-11j, trans-11k, and cis-11a, as well as diastereoisomeric mixtures of isoxazolidines trans-11f/cis-11f (95:5) and trans-11i/cis-11i (92:8), were tested for inhibitory activity against a wide variety of DNA and RNA viruses. The following cell-based assays were used: (a) human embryonic lung (HEL) cells (herpes simplex virus-1 (KOS strain), herpes simplex virus-2 (G strain), thymidine kinase deficient (acyclovir resistant) herpes simplex virus-1 ( $\mathrm{TK}^{-} \mathrm{KOS} \mathrm{ACV}^{\mathrm{r}}$ ), vaccinia virus, adenovirus-2, vesicular stomatitis virus, cytomegalovirus (AD-169 and Davis strains), varicella-zoster virus (TK ${ }^{+}$VZV and TK ${ }^{-}$VZV strains)); (b) HeLa cell cultures (vesicular stomatitis virus, Coxsackie virus B4, and respiratory syncytial virus); (c) Vero cell cultures (parainfluenza-3 virus, reovirus-1, Sindbis virus, Coxsackie virus B4, Punta Toro virus, yellow fever virus); (d) CrFK cell cultures (feline corona virus (FIPV) and feline herpes virus (FHV)); and (e) MDCK cell cultures (influenza A virus (H1N1 and H3N2 subtypes) and influenza B virus). Ganciclovir, cidofovir, acyclovir, brivudin, zalcitabine, zanamivir, alovudine, amantadine, rimantadine, ribavirin, dextran sulfate (molecular weight 10000, DS-10000), mycophenolic acid, Hippeastrum hybrid agglutinin (HHA), and Urtica dioica agglutinin (UDA) were used as the reference compounds. The antiviral activity was expressed as the $\mathrm{EC}_{50}$ : the compound concentration required to reduce virus plaque formation (VZV) by $50 \%$ or to reduce virus-induced cytopathogenicity by $50 \%$ (other viruses). 
Almost all synthesized isoxazolidines inhibited the replication of both $\mathrm{TK}^{+}$and $\mathrm{TK}^{-} \mathrm{VZV}$ strains at $\mathrm{EC}_{50}$ 's in the 5.4-13.6 $\mu \mathrm{M}$ range (Table 2), at the same time they were inactive toward other tested viruses, except for HCMV. In general, the inhibitory activity of the tested compounds toward $\mathrm{TK}^{-}$VZV 07-1 strain was better than that of the reference drugs acyclovir and brivudin $\left(\mathrm{EC}_{50}=39.2 \mu \mathrm{M}\right.$ and $\mathrm{EC}_{50}=31.9 \mu \mathrm{M}$, respectively $)$, which require activation by the viral enzyme. On the other hand, the activity of these compounds against the $\mathrm{TK}^{+} \mathrm{VZV}$ OKA strain was five to nine-fold and 360 to 587-fold lower than that of the reference drugs acyclovir and brivudin, respectively. While exhibiting significant activity toward both $\mathrm{TK}^{+}$and $\mathrm{TK}^{-} \mathrm{VZV}$ stains, compounds trans-11b, trans-11d, trans-11g, and trans-11h exhibited the lowest cytotoxicity $\left(\mathrm{CC}_{50}=33-42 \mu \mathrm{M}\right)$. It is worth mentioning that incorporation of the bromine atom at C6 in the quinazolinone skeleton resulted in a significant increase in potency of isoxazolidine-conjugates $\mathbf{1 1} \mathbf{b}-\mathbf{1 1} \mathbf{i}$ against VZV (up to five-fold higher) when compared with previously described analogous conjugates $\mathbf{1 0 b}-\mathbf{1 0 i}$ having an unsubstituted quinazoline skeleton [25].

Table 2. Antiviral activity and cytotoxicity against varicella-zoster virus (VZV) in HEL cell cultures.

\begin{tabular}{|c|c|c|c|c|c|}
\hline \multirow{2}{*}{ Compound } & \multirow{2}{*}{$\mathbf{R}$} & \multicolumn{2}{|c|}{ Antiviral Activity $\mathrm{EC}_{50}(\mu \mathrm{M})^{\mathrm{a}}$} & \multicolumn{2}{|c|}{ Cytotoxicity $(\mu \mathrm{M})$} \\
\hline & & $\mathrm{TK}^{+}$VZV Strain (OKA) & TK $^{-}$VZV Strain (07-1) & Cell Morphology $\mathrm{MCC}^{\mathrm{b}}$ & Cell Growth $\mathrm{CC}_{50}{ }^{\mathrm{c}}$ \\
\hline cis-11a & $\mathrm{H}$ & $>100$ & $>100$ & $>100$ & n.d. \\
\hline trans-11a & $\mathrm{H}$ & $>100$ & 66.87 & $>100$ & n.d. \\
\hline trans $-\mathbf{1 1} \mathbf{b}$ & $\mathrm{C}_{6} \mathrm{H}_{5}-\mathrm{CH}_{2}$ & $13.5 \pm 7.1$ & $13.6 \pm 9.1$ & 100 & $42.3 \pm 0.3$ \\
\hline trans-11c & $2-\mathrm{NO}_{2}-\mathrm{C}_{6} \mathrm{H}_{4}-\mathrm{CH}_{2}$ & $10.3 \pm 1.1$ & $5.4 \pm 1.0$ & 100 & $9.4 \pm 0.4$ \\
\hline trans-11d & $3-\mathrm{NO}_{2}-\mathrm{C}_{6} \mathrm{H}_{4}-\mathrm{CH}_{2}$ & $8.3 \pm 1.4$ & $5.8 \pm 1.4$ & 100 & $37.0 \pm 4.3$ \\
\hline trans-11e & $4-\mathrm{NO}_{2}-\mathrm{C}_{6} \mathrm{H}_{4}-\mathrm{CH}_{2}$ & 6.84 & 7.51 & 20 & n.d. \\
\hline trans-11f/cis-11f (95:5) & $2-\mathrm{F}-\mathrm{C}_{6} \mathrm{H}_{4}-\mathrm{CH}_{2}$ & 7.76 & 9.56 & 20 & n.d. \\
\hline trans-11g & $3-\mathrm{F}-\mathrm{C}_{6} \mathrm{H}_{4}-\mathrm{CH}_{2}$ & $11.6 \pm 5.3$ & $7.7 \pm 6.2$ & $>20$ & $33.0 \pm 3.5$ \\
\hline trans-11h & $4-\mathrm{F}-\mathrm{C}_{6} \mathrm{H}_{4}-\mathrm{CH}_{2}$ & $12.6 \pm 2.6$ & $7.5 \pm 5.4$ & $>20$ & $39.4 \pm 5.2$ \\
\hline trans-11i/cis-11i (92:8) & 2,4-diF- $\mathrm{C}_{6} \mathrm{H}_{3}-{ }^{-} \mathrm{CH}_{2}$ & $8.7 \pm 3.2$ & $10.5 \pm 0.3$ & $>20$ & $15.6 \pm 3.2$ \\
\hline trans $-\mathbf{1 1} \mathbf{j}$ & $\mathrm{CH}_{3}$ & $>4$ & $>4$ & 20 & n.d. \\
\hline trans-11k & $\mathrm{CH}_{3} \mathrm{CH}_{2}$ & $>20$ & $>20$ & 100 & n.d. \\
\hline Acyclovir & & $1.55 \pm 1.0$ & $39.2 \pm 3.6$ & $>440$ & $>350$ \\
\hline Brivudin & & $0.023 \pm 0.008$ & $31.9 \pm 16.1$ & $>300$ & $>300$ \\
\hline
\end{tabular}

${ }^{a}$ Effective concentration required to reduce virus plaque formation by $50 \%$. Virus input was 100 plaque forming units (PFU), ${ }^{b}$ Minimum cytotoxic concentration that causes a microscopically detectable alternation of cell morphology, ${ }^{\mathrm{c}}$ Cytotoxic concentrations required to reduce cell growth by $50 \%$, n.d.- not determined.

The synthesized isoxazolidine phosphonates also showed marked activity against human cytomegalovirus (HCMV) (Table 3) and, among them, trans-11d, trans-11g, trans-11h, and trans-11i/cis-11i (92:8) were the most potent ones. Activities of the tested compounds against both AD-169 and Davis strains were comparable $\left(\mathrm{EC}_{50}=8.9-12.5 \mu \mathrm{M}\right)$ to that of Ganciclovir $\left(\mathrm{EC}_{50}=16.9\right.$ and $\left.7.7 \mu \mathrm{M}\right)$ used as a reference drug, but still lower than that of the other reference drug, Cidofovir $\left(\mathrm{EC}_{50}=1.5-1.7 \mu \mathrm{M}\right)$.

Table 3. Antiviral activity and cytotoxicity against human cytomegalovirus in HEL cell cultures.

\begin{tabular}{|c|c|c|c|c|c|}
\hline \multirow{2}{*}{ Compound } & \multirow{2}{*}{$\mathbf{R}$} & \multicolumn{2}{|c|}{ Antiviral Activity $\mathrm{EC}_{50}(\mu \mathrm{M})^{\mathrm{a}}$} & \multicolumn{2}{|c|}{ Cytotoxicity $(\mu \mathrm{M})$} \\
\hline & & AD-169 Strain & Davis Strain & Cell Morphology MCC $^{b}$ & Cell Growth $\mathrm{CC}_{50}{ }^{\mathrm{c}}$ \\
\hline cis-11a & $\mathrm{H}$ & $>100$ & 100 & 20 & n.d. \\
\hline trans-11a & $\mathrm{H}$ & $>100$ & $>100$ & 100 & n.d. \\
\hline trans-11b & $\mathrm{C}_{6} \mathrm{H}_{5}-\mathrm{CH}_{2}$ & 20 & 20 & 20 & n.d. \\
\hline trans-11c & $2-\mathrm{NO}_{2}-\mathrm{C}_{6} \mathrm{H}_{4}-\mathrm{CH}_{2}$ & $>20$ & 15.29 & 100 & n.d. \\
\hline trans-11d & $3-\mathrm{NO}_{2}-\mathrm{C}_{6} \mathrm{H}_{4}-\mathrm{CH}_{2}$ & $10.4 \pm 0.8$ & $11.6 \pm 2.5$ & 100 & $37.0 \pm 4.3$ \\
\hline trans-11e & $4-\mathrm{NO}_{2}-\mathrm{C}_{6} \mathrm{H}_{4}-\mathrm{CH}_{2}$ & $>20$ & $>20$ & 100 & n.d. \\
\hline trans-11f/cis-11f (95:5) & $2-\mathrm{F}-\mathrm{C}_{6} \mathrm{H}_{4}-\mathrm{CH}_{2}$ & 8.94 & 8.94 & 20 & n.d. \\
\hline trans-11g & $3-\mathrm{F}-\mathrm{C}_{6} \mathrm{H}_{4}-\mathrm{CH}_{2}$ & $10.5 \pm 2.2$ & $8.94 \pm 0$ & 100 & $33.0 \pm 3.5$ \\
\hline trans-11h & $4-\mathrm{F}-\mathrm{C}_{6} \mathrm{H}_{4}-\mathrm{CH}_{2}$ & $12.5 \pm 3.9$ & $11.2 \pm 3.1$ & 100 & $39.4 \pm 5.2$ \\
\hline trans-11i/cis-11i (92:8) & $2,4-\mathrm{diF}-\mathrm{C}_{6} \mathrm{H}_{3}-\mathrm{CH}_{2}$ & $9.4 \pm 0.46$ & $9.7 \pm 1.1$ & $>20$ & $15.6 \pm 3.2$ \\
\hline trans $-\mathbf{1 1} \mathbf{j}$ & $\mathrm{CH}_{3}$ & $>20$ & $>100$ & 20 & n.d. \\
\hline trans-11k & $\mathrm{CH}_{3} \mathrm{CH}_{2}$ & $>20$ & 44.72 & 20 & n.d. \\
\hline Ganciclovir & & $16.9 \pm 6.9$ & $7.7 \pm 0.9$ & $>350$ & $>350$ \\
\hline Cidofovir & & $1.5 \pm 0.2$ & $1.7 \pm 0.4$ & $>300$ & $>300$ \\
\hline
\end{tabular}

a Effective concentration required to reduce virus plaque formation by $50 \%$. Virus input was 100 plaque forming units (PFU), ${ }^{b}$ Minimum cytotoxic concentration that causes a microscopically detectable alternation of cell morphology, ${ }^{\mathrm{c}}$ Cytotoxic concentrations required to reduce cell growth by $50 \%$, n.d.- not determined. 


\subsubsection{Cytostatic Activity}

The $50 \%$ cytostatic inhibitory concentration $\left(\mathrm{IC}_{50}\right)$ causing a $50 \%$ decrease in cell proliferation was determined against murine leukemia L1210, human lymphocyte CEM, human cervix carcinoma HeLa, and immortalized human dermal microvacsular endothelial cells (HMEC-1). Almost all compounds 11a-11k showed inhibitory activity against the proliferation of tumour cell lines (Table 4). They appeared to be the most cytostatic toward the human T-lymphocyte (CEM) cell line with an inhibitory effect in the 9.6-33 $\mu \mathrm{M}$ range. Thus, isoxazolidines trans-11b $\left(\mathrm{IC}_{50}=16 \pm 3 \mu \mathrm{M}\right)$, trans-11c $\left(\mathrm{IC}_{50}=14 \pm 4 \mu \mathrm{M}\right)$, trans-11e $\left(\mathrm{IC}_{50}=17 \pm 12 \mu \mathrm{M}\right)$, trans-11f $/$ cis-11f $(95: 5)\left(\mathrm{IC}_{50}=13 \pm 1 \mu \mathrm{M}\right)$, trans-11g $\left(\mathrm{IC}_{50}=10 \pm 0 \mu \mathrm{M}\right)$, trans-11h $\left(\mathrm{IC}_{50}=9.6 \pm 2.2 \mu \mathrm{M}\right)$, and trans-11i $/$ cis-11i $(92: 8)\left(\mathrm{IC}_{50}=9.8 \pm 4.8 \mu \mathrm{M}\right)$ exhibited activity toward the CEM line higher than of 5-fluorouracil $\left(\mathrm{IC}_{50}=18 \pm 5 \mu \mathrm{M}\right)$.

Table 4. Inhibitory effect of the tested compounds against the proliferation of murine leukemia (L1210), human T-lymphocyte (CEM), human cervix carcinoma (HeLa), and immortalized human dermal microvascular endothelial cells (HMEC-1).

\begin{tabular}{|c|c|c|c|c|c|}
\hline \multirow{2}{*}{ Compound } & \multirow{2}{*}{$\mathbf{R}$} & \multicolumn{4}{|c|}{$\mathrm{IC}_{50}{ }^{\mathrm{a}}(\mu \mathrm{M})$} \\
\hline & & L1210 & CEM & HeLa & HMEC-1 \\
\hline cis-11a & $\mathrm{H}$ & $>250$ & $242 \pm 7$ & $>250$ & $140 \pm 54$ \\
\hline trans-11a & $\mathrm{H}$ & $126 \pm 19$ & $148 \pm 2$ & $196 \pm 20$ & $85 \pm 13$ \\
\hline trans-11b & $\mathrm{C}_{6} \mathrm{H}_{5}-\mathrm{CH}_{2}$ & $20 \pm 2$ & $16 \pm 3$ & $26 \pm 7$ & $30 \pm 0$ \\
\hline trans-11c & $2-\mathrm{NO}_{2}-\mathrm{C}_{6} \mathrm{H}_{4}-\mathrm{CH}_{2}$ & $19 \pm 3$ & $14 \pm 4$ & $22 \pm 11$ & $30 \pm 0$ \\
\hline trans-11d & $3-\mathrm{NO}_{2}-\mathrm{C}_{6} \mathrm{H}_{4}-\mathrm{CH}_{2}$ & $26 \pm 1$ & $33 \pm 25$ & $24 \pm 9$ & $30 \pm 0$ \\
\hline trans-11e & $4-\mathrm{NO}_{2}-\mathrm{C}_{6} \mathrm{H}_{4}-\mathrm{CH}_{2}$ & $18 \pm 76$ & $17 \pm 12$ & $24 \pm 9$ & $26 \pm 6$ \\
\hline trans-11f/cis-11f (95:5) & $2-\mathrm{F}-\mathrm{C}_{6} \mathrm{H}_{4}-\mathrm{CH}_{2}$ & $17 \pm 2$ & $13 \pm 1$ & $25 \pm 7$ & $30 \pm 0$ \\
\hline trans-11g & $3-\mathrm{F}-\mathrm{C}_{6} \mathrm{H}_{4}-\mathrm{CH}_{2}$ & $16 \pm 2$ & $10 \pm 0$ & $25 \pm 7$ & $30 \pm 0$ \\
\hline trans-11h & $4-\mathrm{F}-\mathrm{C}_{6} \mathrm{H}_{4}-\mathrm{CH}_{2}$ & $16 \pm 0$ & $9.6 \pm 2.2$ & $25 \pm 7$ & $29 \pm 1$ \\
\hline trans-11i/cis-11i (92:8) & 2,4-diF- $\mathrm{C}_{6} \mathrm{H}_{3}-\mathrm{CH}_{2}$ & $16 \pm 1$ & $9.8 \pm 4.8$ & $22 \pm 6$ & $30 \pm 0$ \\
\hline trans-11j & $\mathrm{CH}_{3}$ & $138 \pm 19$ & $128 \pm 21$ & $175 \pm 105$ & $>250$ \\
\hline trans-11k/cis-11k (97:3) & $\mathrm{CH}_{3} \mathrm{CH}_{2}$ & $102 \pm 14$ & $44 \pm 18$ & $113 \pm 44$ & $121 \pm 41$ \\
\hline 5-Fluorouracil & & $0.33 \pm 0.17$ & $18 \pm 5$ & $0.54 \pm 0.12$ & n.d. \\
\hline
\end{tabular}

a $50 \%$ Inhibitory concentration or compound concentration required to inhibit tumor cell proliferation by $50 \%$, n.d.-not determined.

Structure-activity relationship studies indicated that the isoxazolidine derivatives possessing hydrogen (cis-11a, trans-11a), methyl (trans-11j), or ethyl (trans-11k) at N3 in the quinazolinone ring were not active against tested viruses and they did not inhibit proliferation of the tested cell lines. Compounds substituted at N3 with benzyl moieties were found effective against VZV, HCMV, and were able to inhibit tumour cell line growth. Moreover, isoxazolidine phosphonates having 3-nitrobenzyl (trans-11d) and 3-fluorobenzyl (trans-11g) substituents at N3 of the quinazolinone core showed the highest antiviral activity with an $\mathrm{EC}_{50}$ values in the range of 5.8-11.6 $\mu \mathrm{M}$.

On the other hand, compounds possessing 3-fluorobenzyl (trans-11g), 4-fluorobenzyl (trans-11h) and 2,4-difluorobenzyl (trans-11i/cis-11i (92:8)) substituents at the N3 position showed an inhibitory effect against the proliferation of murine leukemia (L1210) and human T-lymphocyte (CEM) cell lines, whereas isoxazolidines having 2-nitrobenzyl (trans-11c) and 2,4-difluorobenzyl (trans-11i/cis-11i (92:8)) substituents at the same position of a quinazolinone moiety appeared to be the most active toward the human cervix carcinoma (HeLa) cell line, however, their inhibitory concentration was much lower than that of the reference drugs.

\section{Experimental Section}

\subsection{General}

${ }^{1} \mathrm{H}-\mathrm{NMR}$ spectra were taken in $\mathrm{CDCl}_{3}$ on the following spectrometers: Gemini 2000BB (200 MHz Varian, Palo Alto, CA, USA), and Bruker Avance III (600 MHz, Bruker Instrument, Karlsruhe, Germany) 
with TMS as internal standard. ${ }^{13} \mathrm{C}-\mathrm{NMR}$ spectra were recorded for $\mathrm{CDCl}_{3}$ solution on the Bruker Avance III at $151.0 \mathrm{MHz} .{ }^{31} \mathrm{P}-\mathrm{NMR}$ spectra were performed in $\mathrm{CDCl}_{3}$ solution on the Varian Gemini $2000 \mathrm{BB}$ at $81.0 \mathrm{MHz}$ or on Bruker Avance III at 243.0 MHz.

IR spectra were measured on an Infinity MI-60 FT-IR spectrometer (ATI Instruments North America-Mattson, Madison, WI, USA). Melting points were determined on a Boetius apparatus (VEB Kombinat NAGEMA, Dresden, DDR-currently Germany) and are uncorrected. Elemental analyses were performed by the Microanalytical Laboratory of this faculty on a Perkin-Elmer PE 2400 CHNS analyzer (Perkin-Elmer Corp., Norwalk, CT, USA).

The following adsorbents were used: column chromatography, Merck silica gel 60 (70-230 mesh); analytical TLC, Merck (Merck KGaA, Darmstadt, Germany) TLC plastic sheet silica gel $60 \mathrm{~F}_{254}$.

$\mathrm{N}$-methyl-C-(diethoxyphosphoryl)nitrone [26] and 5-bromoanthranilic acid amide $[27,28]$ were obtained according to the procedures in the literature.

\subsection{Synthesis of 6-Bromo-2-vinyl-3H-quinazolin-4-one 13a}

To a solution 5-bromoanthranilic amide ( $2.40 \mathrm{~g}, 11.2 \mathrm{mmol})$ in 1,4-dioxane $(5 \mathrm{~mL})$ 3-chloropropionyl chloride $(0.527 \mathrm{~mL}, 5.60 \mathrm{mmol})$ was added over $20 \mathrm{~min}$. at $0{ }^{\circ} \mathrm{C}$ under an argon atmosphere. The mixture was stirred at room temperature for $1 \mathrm{~h}$ and then diluted with water until a precipitate appeared, which was collected and washed with water $(3 \times 10 \mathrm{~mL})$. A mixture of 2-(3-chloropropionylamino)benzamide $(2.03 \mathrm{~g}$, $6.63 \mathrm{mmol})$ in $5 \%$ sodium hydroxide $(16.4 \mathrm{~mL})$ and ethanol $(8.2 \mathrm{~mL})$ was stirred under reflux for $5 \mathrm{~min}$., the solution was allowed to cool for $15 \mathrm{~min}$. and then acidified with acetic acid (1.6 mL). The precipitate was collected and washed with water $(3 \times 10 \mathrm{~mL})$. The crude 6-bromo-2-vinylquinazolin-4(3H)-one was purified by crystallization from methanol.

Off-white amorphous solid, m.p. $=223-225^{\circ} \mathrm{C}$ (re-crystallized from methanol). IR $\left(\mathrm{KBr}, \mathrm{cm}^{-1}\right) v_{\max }$ : 3165, 3088, 3019, 2943, 2738, 1673, 1638, 1591, 1462, 1337, 1292, 1245, 1207, 1114, 1065, 977, 829, 793, 687, 633. ${ }^{1} \mathrm{H}-\mathrm{NMR}(200 \mathrm{MHz}, \mathrm{DMSO}): \delta=12.51(\mathrm{~s}, 1 \mathrm{H}, \mathrm{NH}), 8.17\left(\mathrm{~d},{ }^{4} J=2.4 \mathrm{~Hz}, 1 \mathrm{H}, \mathrm{HC} 5\right), 7.90\left(\mathrm{dd},{ }^{3} J=8.7 \mathrm{~Hz}\right.$, $\left.{ }^{4} J=2.4 \mathrm{~Hz}, 1 \mathrm{H}, \mathrm{HC7}\right), 7.81\left(\mathrm{~d},{ }^{3} \mathrm{~J}=8.7 \mathrm{~Hz}, 1 \mathrm{H}, \mathrm{HC} 8\right), 6.63\left(\mathrm{dd},{ }^{3} \mathrm{~J}=17.5 \mathrm{~Hz},{ }^{2} \mathrm{~J}=3.7 \mathrm{~Hz}, 1 \mathrm{H}, \mathrm{CH}=\mathrm{CH}_{2}\right), 6.53$ $\left(\mathrm{dd},{ }^{3} \mathrm{~J}=17.5 \mathrm{~Hz},{ }^{3} \mathrm{~J}=8.1 \mathrm{~Hz}, 1 \mathrm{H}, \mathrm{CH}=\mathrm{CH}_{2}\right), 5.86\left(\mathrm{dd},{ }^{3} \mathrm{~J}=8.1 \mathrm{~Hz},{ }^{2} \mathrm{~J}=3.7 \mathrm{~Hz}, 1 \mathrm{H}, \mathrm{CH}=\mathrm{CH}_{2}\right) .{ }^{13} \mathrm{C}-\mathrm{NMR}$ (151 MHz, DMSO): $\delta=161.11$ (C=O), 152.00, 148.23, 137.80, 131.00, 130.18, 128.45, 126.31, 123.40, 119.37 . Anal. Calcd. for $\mathrm{C}_{10} \mathrm{H}_{7} \mathrm{BrN}_{2} \mathrm{O}$ : C, 47.84; $\mathrm{H}, 2.81 ; \mathrm{N}, 11.16$. Found: $\mathrm{C}, 47.88 ; \mathrm{H}, 2.49 ; \mathrm{N}, 11.01$.

\subsection{General Procedure for the Synthesis of N3-Benzylated 6-bromo-2-vinyl-3H-quinazolin-4-ones 13b-13i}

To a solution of 6-bromo-2-vinyl-3H-quinazolin-4-one $(0.251 \mathrm{~g}$, $1.00 \mathrm{mmol})$ in acetonitrile $(15 \mathrm{~mL})$ potassium hydroxide $(0.168 \mathrm{~g}, 3.00 \mathrm{mmol})$ was added. After $15 \mathrm{~min}$. the respective benzyl bromide $(1.10 \mathrm{mmol})$ was added and the reaction mixture was stirred under reflux for $4 \mathrm{~h}$. The solvent was removed and the residue was re-dissolved in methylene chloride $(10 \mathrm{~mL})$ and extracted with water $(3 \times 10 \mathrm{~mL})$. An organic phase was dried $\left(\mathrm{MgSO}_{4}\right)$, concentrated, and the crude product was purified on a silica gel column with a methylene chloride:hexane $(7: 3, v / v)$ mixture followed by crystallization (chloroform-petroleum ether or ethyl acetate) to give pure quinazolinones.

3-Benzyl-6-bromo-2-vinylquinazolin-4(3H)-one (13b). A white amorphous solid, m.p. $=71-72{ }^{\circ} \mathrm{C}$ (re-crystallized from ethyl acetate). IR $\left(\mathrm{KBr}, \mathrm{cm}^{-1}\right) v_{\max }: 3097,3036,2926,1608,1571,1553,1470$, 1290, 1153, 1112, 989, 841, 678, 581, 437. ${ }^{1} \mathrm{H}-\mathrm{NMR}\left(200 \mathrm{MHz}, \mathrm{CDCl}_{3}\right): \delta=8.30-8.27(\mathrm{~m}, 1 \mathrm{H}), 7.88-7.82$ $(\mathrm{m}, 1 \mathrm{H}), 7.77-7.73(\mathrm{~m}, 1 \mathrm{H}), 7.57-7.50(\mathrm{~m}, 2 \mathrm{H}), 7.48-7.37(\mathrm{~m}, 3 \mathrm{H}), 6.91\left(\mathrm{dd},{ }^{3} \mathrm{~J}=17.2 \mathrm{~Hz},{ }^{3} \mathrm{~J}=9.9 \mathrm{~Hz}\right.$, $\left.1 \mathrm{H}, \mathrm{CH}=\mathrm{CH}_{2}\right), 6.73\left(\mathrm{dd},{ }^{3} \mathrm{~J}=17.2 \mathrm{~Hz},{ }^{2} J=2.5 \mathrm{~Hz}, 1 \mathrm{H}, \mathrm{CH}=\mathrm{CH}_{2}\right), 5.82\left(\mathrm{dd},{ }^{3} \mathrm{~J}=9.9 \mathrm{~Hz},{ }^{2} \mathrm{~J}=2.5 \mathrm{~Hz}, 1 \mathrm{H}\right.$, $\left.\mathrm{CH}=\mathrm{CH}_{2}\right), 5.67\left(\mathrm{~s}, 2 \mathrm{H}, \mathrm{N}-\mathrm{CH}_{2}\right) .{ }^{13} \mathrm{C}-\mathrm{NMR}\left(151 \mathrm{MHz} \mathrm{CDCl}_{3}\right): \delta=165.16(\mathrm{C}=\mathrm{O}), 160.28,150.36,137.00$, $136.88,136.02,129.45,128.67,128.45,126.09,124.36,120.03,116.67,68.69\left(\mathrm{~N}_{-} \mathrm{CH}_{2}\right)$. Anal. Calcd. for $\mathrm{C}_{17} \mathrm{H}_{13} \mathrm{BrN}_{2} \mathrm{O}: \mathrm{C}, 59.84 ; \mathrm{H}, 3.84 ; \mathrm{N}, 8.21$. Found: $\mathrm{C}, 59.92 ; \mathrm{H}, 3.68 ; \mathrm{N}, 8.29$.

6-Bromo-3-(2-nitrobenzyl)-2-vinylquinazolin-4(3H)-one (13c). A yellowish amorphous solid, m.p. 117-119 ${ }^{\circ} \mathrm{C}$ (re-crystallized from chloroform-petroleum ether). IR $\left(\mathrm{KBr}, \mathrm{cm}^{-1}\right) v_{\max }: 3078,2980$, 2925, 2854, 1689, 1613, 1573, 1526, 1489, 1390, 1354, 1287, 1242, 1116, 1053, 1024, 968, 836, 791, 730. 
${ }^{1} \mathrm{H}-\mathrm{NMR}\left(600 \mathrm{MHz}, \mathrm{CDCl}_{3}\right): \delta=8.33\left(\mathrm{~d},{ }^{4} J=2.2 \mathrm{~Hz}, 1 \mathrm{H}, \mathrm{HC} 5\right), 8.18-8.16(\mathrm{~m}, 1 \mathrm{H}), 7.90\left(\mathrm{dd},{ }^{3} J=8.9 \mathrm{~Hz}\right.$, $\left.{ }^{4} J=2.2 \mathrm{~Hz}, 1 \mathrm{H}, \mathrm{HC} 7\right), 7.81\left(\mathrm{~d},{ }^{3} \mathrm{~J}=8.9 \mathrm{~Hz}, 1 \mathrm{H}, \mathrm{HC} 8\right), 7.80-7.78(\mathrm{~m}, 1 \mathrm{H}), 7.71-7.69(\mathrm{~m}, 1 \mathrm{H}), 7.56-7.53$ $(\mathrm{m}, 1 \mathrm{H}), 6.87\left(\mathrm{dd},{ }^{3} J=17.2 \mathrm{~Hz},{ }^{3} J=10.4 \mathrm{~Hz}, 1 \mathrm{H}, \mathrm{CH}=\mathrm{CH}_{2}\right), 6.64\left(\mathrm{dd},{ }^{3} J=17.2 \mathrm{~Hz},{ }^{2} J=1.5 \mathrm{~Hz}, 1 \mathrm{H}\right.$, $\left.\mathrm{CH}=\mathrm{CH}_{2}\right), 6.10\left(\mathrm{~s}, 2 \mathrm{H}, \mathrm{N}-\mathrm{CH}_{2}\right), 5.80\left(\mathrm{dd},{ }^{3} \mathrm{~J}=10.4 \mathrm{~Hz},{ }^{2} \mathrm{~J}=1.5 \mathrm{~Hz}, 1 \mathrm{H}, \mathrm{CH}=\mathrm{CH}_{2}\right) .{ }^{13} \mathrm{C}-\mathrm{NMR}(151 \mathrm{MHz}$, $\left.\mathrm{CDCl}_{3}\right): \delta=164.62(\mathrm{C}=\mathrm{O}), 160.12,150.32,147.84,137.31,136.31,133.78,132.33,129.51,129.05,128.87$, 125.76, 125.07, 124.92, 120.38, 116.31, $65.14\left(\mathrm{~N}^{-} \mathrm{CH}_{2}\right)$. Anal. Calcd. for $\mathrm{C}_{17} \mathrm{H}_{12} \mathrm{BrN}_{3} \mathrm{O}_{3}: \mathrm{C}, 52.87 ; \mathrm{H}, 3.13$; $\mathrm{N}, 10.88$. Found: $\mathrm{C}, 52.50 ; \mathrm{H}, 2.80 ; \mathrm{N}, 10.80$.

6-Bromo-3-(3-nitrobenzyl)-2-vinylquinazolin-4(3H)-one (13d). A yellowish amorphous solid, m.p. 147-149 ${ }^{\circ} \mathrm{C}$ (re-crystallized from chloroform-petroleum ether). IR $\left(\mathrm{KBr}, \mathrm{cm}^{-1}\right) v_{\max }$ : 3112, 3071, 2924, 2854, 1610, 1573, 1529, 1456, 1382, 1294, 1119, 836, 668. ${ }^{1} \mathrm{H}-\mathrm{NMR}\left(600 \mathrm{MHz}, \mathrm{CDCl}_{3}\right): \delta=8.44$ (brs, $1 \mathrm{H}), 8.32-8.30(\mathrm{~m}, 1 \mathrm{H}), 8.26-8.24(\mathrm{~m}, 1 \mathrm{H}), 7.91-7.88(\mathrm{~m}, 2 \mathrm{H}), 7.80-7.78(\mathrm{~m}, 1 \mathrm{H}), 7.64-7.61(\mathrm{~m}, 1 \mathrm{H})$, $6.91\left(\mathrm{dd},{ }^{3} \mathrm{~J}=17.2 \mathrm{~Hz},{ }^{3} \mathrm{~J}=10.4 \mathrm{~Hz}, 1 \mathrm{H}, \mathrm{CH}=\mathrm{CH}_{2}\right), 6.73\left(\mathrm{dd},{ }^{3} \mathrm{~J}=17.2 \mathrm{~Hz},{ }^{2} \mathrm{~J}=1.4 \mathrm{~Hz}, 1 \mathrm{H}, \mathrm{CH}=\mathrm{CH}_{2}\right)$, $5.84\left(\mathrm{dd},{ }^{3} \mathrm{~J}=10.4 \mathrm{~Hz},{ }^{2} \mathrm{~J}=1.4 \mathrm{~Hz}, 1 \mathrm{H}, \mathrm{CH}=\mathrm{CH}_{2}\right), 5.78\left(\mathrm{~s}, 2 \mathrm{H}, \mathrm{N}-\mathrm{CH}_{2}\right) .{ }^{13} \mathrm{C}-\mathrm{NMR}\left(151 \mathrm{MHz}, \mathrm{CDCl}_{3}\right)$ : $\delta=164.69(\mathrm{C}=\mathrm{O}), 160.05,150.49,148.51,138.14,137.28,136.68,134.10,129.73,129.60,125.84,124.47$, 123.37, 123.27, 120.35, 116.34, 67.22 (N-CH$)$. Anal. Calcd. for $\mathrm{C}_{17} \mathrm{H}_{12} \mathrm{BrN}_{3} \mathrm{O}_{3}: \mathrm{C}, 52.87 ; \mathrm{H}, 3.13 ; \mathrm{N}$, 10.88. Found: $\mathrm{C}, 52.81 ; \mathrm{H}, 2.98 ; \mathrm{N}, 10.60$.

6-Bromo-3-(4-nitrobenzyl)-2-vinylquinazolin-4(3H)-one (13e). Off-white amorphous solid, m.p. 121-123 ${ }^{\circ} \mathrm{C}$ (re-crystallized from chloroform-petroleum ether). IR $\left(\mathrm{KBr}, \mathrm{cm}^{-1}\right) v_{\text {max }}: 3418,2924,2853,1739,1608$, $1573,1524,1343,1292,1117,945,833,661 .{ }^{1} \mathrm{H}-\mathrm{NMR}\left(200 \mathrm{MHz}, \mathrm{CDCl}_{3}\right): \delta=8.30-8.26(\mathrm{~m}, 3 \mathrm{H}), 7.96-7.92$ $(\mathrm{m}, 1 \mathrm{H}), 7.81-7.76(\mathrm{~m}, 1 \mathrm{H}), 7.73-7.67(\mathrm{~m}, 2 \mathrm{H}), 6.88\left(\mathrm{dd},{ }^{3} \mathrm{~J}=17.2 \mathrm{~Hz},{ }^{3} \mathrm{~J}=10.1 \mathrm{~Hz}, 1 \mathrm{H}, \mathrm{CH}=\mathrm{CH}_{2}\right)$, $6.65\left(\mathrm{dd},{ }^{3} \mathrm{~J}=17.2 \mathrm{~Hz},{ }^{2} \mathrm{~J}=2.1 \mathrm{~Hz}, 1 \mathrm{H}, \mathrm{CH}=\mathrm{CH}_{2}\right), 5.80\left(\mathrm{dd},{ }^{3} \mathrm{~J}=10.1 \mathrm{~Hz},{ }^{2} \mathrm{~J}=2.1 \mathrm{~Hz}, 1 \mathrm{H}, \mathrm{CH}=\mathrm{CH}_{2}\right)$, $5.77\left(\mathrm{~s}, 2 \mathrm{H}, \mathrm{N}-\mathrm{CH}_{2}\right) .{ }^{13} \mathrm{C}-\mathrm{NMR}\left(151 \mathrm{MHz}, \mathrm{CDCl}_{3}\right): \delta=164.69(\mathrm{C}=\mathrm{O}), 160.03,150.41,147.93,143.27$, 137.37, 136.59, 129.58, 128.50, 125.80, 124.58, 123.93, 120.44, 116.33, $67.14\left(\mathrm{~N}-\mathrm{CH}_{2}\right)$. Anal. Calcd. for $\mathrm{C}_{17} \mathrm{H}_{12} \mathrm{BrN}_{3} \mathrm{O}_{3}: \mathrm{C}, 52.87 ; \mathrm{H}, 3.13 ; \mathrm{N}, 10.88$. Found: $\mathrm{C}, 52.81 ; \mathrm{H}, 2.98 ; \mathrm{N}, 10.60$.

6-Bromo-3-(2-fluorobenzyl)-2-vinylquinazolin-4(3H)-one (13f). A white amorphous solid, m.p. $91-92{ }^{\circ} \mathrm{C}$ (re-crystallized from ethyl acetate). IR (KBr, cm $\left.{ }^{-1}\right) v_{\max }$ : 3078, 2967, 1568, 1555, 1486, 1420, 1348, 1293, $1238,1115,938,828,760,675 .{ }^{1} \mathrm{H}-\mathrm{NMR}\left(600 \mathrm{MHz}, \mathrm{CDCl}_{3}\right): \delta=8.31\left(\mathrm{~d},{ }^{4} J=2.2 \mathrm{~Hz}, 1 \mathrm{H}, \mathrm{HC} 5\right), 7.89$ $\left(\mathrm{dd},{ }^{3} J=8.9 \mathrm{~Hz},{ }^{4} J=2.2 \mathrm{~Hz}, 1 \mathrm{H}, H C 7\right), 7.68\left(\mathrm{~d},{ }^{3} \mathrm{~J}=8.9 \mathrm{~Hz}, 1 \mathrm{H}, \mathrm{HC} 8\right), 7.61-7.58(\mathrm{~m}, 1 \mathrm{H}), 7.42-7.38$ $(\mathrm{m}, 1 \mathrm{H}), 7.23-7.20(\mathrm{~m}, 1 \mathrm{H}), 7.18-7.15(\mathrm{~m}, 1 \mathrm{H}), 6.92\left(\mathrm{dd},{ }^{3} \mathrm{~J}=17.2 \mathrm{~Hz},{ }^{3} \mathrm{~J}=10.4 \mathrm{~Hz}, 1 \mathrm{H}, \mathrm{CH}=\mathrm{CH}_{2}\right), 6.78$ $\left(\mathrm{dd},{ }^{3} \mathrm{~J}=17.2 \mathrm{~Hz},{ }^{2} \mathrm{~J}=1.7 \mathrm{~Hz}, 1 \mathrm{H}, \mathrm{CH}=\mathrm{CH}_{2}\right), 5.84\left(\mathrm{dd},{ }^{3} \mathrm{~J}=10.4 \mathrm{~Hz},{ }^{2} \mathrm{~J}=1.7 \mathrm{~Hz}, 1 \mathrm{H}, \mathrm{CH}=\mathrm{CH}_{2}\right), 5.78$ $\left(\mathrm{s}, 2 \mathrm{H}, \mathrm{N}-\mathrm{CH}_{2}\right) .{ }^{13} \mathrm{C}-\mathrm{NMR}\left(151 \mathrm{MHz}, \mathrm{CDCl}_{3}\right): \delta=164.99(\mathrm{C}=\mathrm{O}), 161.20\left(\mathrm{~d},{ }^{1} J_{(\mathrm{CF})}=248.8 \mathrm{~Hz}, \mathrm{C}^{\prime}\right)$, $160.24,150.39,137.03,136.81,130.70\left(\mathrm{~d},{ }^{3} J_{(\mathrm{CCCF})}=4.0 \mathrm{~Hz}, \mathrm{C} 4^{\prime}\right), 130.39\left(\mathrm{~d},{ }^{3} J_{(\mathrm{CCCF})}=7.9 \mathrm{~Hz}, \mathrm{C}^{\prime}\right), 129.47$, $126.04,124.44,124.25\left(\mathrm{~d},{ }^{4} J_{(\mathrm{CCCCF})}=3.4 \mathrm{~Hz}, \mathrm{C}^{\prime}\right), 123.24\left(\mathrm{~d},{ }^{2} J_{(\mathrm{CCF})}=14.5 \mathrm{~Hz}, \mathrm{C} 3^{\prime}\right), 120.06,116.59,115.63$ $\left(\mathrm{d}^{2} \mathrm{~J}_{(\mathrm{CCF})}=21.5 \mathrm{~Hz}, \mathrm{C1} 1^{\prime}\right), 62.51\left(\mathrm{~d},{ }^{3} \mathrm{~J}_{(\mathrm{CCF})}=4.4 \mathrm{~Hz}, \mathrm{~N}-\mathrm{CH}_{2}\right)$. Anal. Calcd. for $\mathrm{C}_{17} \mathrm{H}_{12} \mathrm{BrFN}_{2} \mathrm{O}: \mathrm{C}, 56.85$; $\mathrm{H}, 3.37 ; \mathrm{N}, 7.80$. Found: C, 56.62; H, 2.99; N, 7.79.

6-Bromo-3-(3-fluorobenzyl)-2-vinylquinazolin-4(3H)-one (13g). A yellowish amorphous solid, m.p. 78-80 ${ }^{\circ} \mathrm{C}$ (re-crystallized from ethyl acetate). IR $\left(\mathrm{KBr}, \mathrm{cm}^{-1}\right) v_{\max }: 3070,2980,2925,2853,1614,1568$, 1490, 1416, 1336, 1286, 1115, 1055, 967, 836, 790. ${ }^{1} \mathrm{H}-\mathrm{NMR}\left(600 \mathrm{MHz}, \mathrm{CDCl}_{3}\right): \delta=8.32\left(\mathrm{~d},{ }^{4} J=2.2 \mathrm{~Hz}\right.$, $1 \mathrm{H}, H C 5), 7.89\left(\mathrm{dd},{ }^{3} J=8.9 \mathrm{~Hz},{ }^{4} J=2.2 \mathrm{~Hz}, 1 \mathrm{H}, H C 7\right), 7.80\left(\mathrm{~d},{ }^{3} J=8.9 \mathrm{~Hz}, 1 \mathrm{H}, H C 8\right), 7.43-7.39(\mathrm{~m}, 1 \mathrm{H})$, 7.34-7.32 (m, 1H), 7.28-7.26 (m, 1H), 7.11-7.08 (m, 1H), $6.92\left(\mathrm{dd},{ }^{3} \mathrm{~J}=17.1 \mathrm{~Hz},{ }^{3} \mathrm{~J}=10.4 \mathrm{~Hz}, 1 \mathrm{H}, \mathrm{CH}=\mathrm{CH}_{2}\right)$, $6.73\left(\mathrm{dd},{ }^{3} \mathrm{~J}=17.1 \mathrm{~Hz},{ }^{2} \mathrm{~J}=1.7 \mathrm{~Hz}, 1 \mathrm{H}, \mathrm{CH}=\mathrm{CH}_{2}\right), 5.84\left(\mathrm{dd},{ }^{3} \mathrm{~J}=10.4 \mathrm{~Hz},{ }^{2} \mathrm{~J}=1.7 \mathrm{~Hz}, 1 \mathrm{H}, \mathrm{CH}=\mathrm{CH}_{2}\right)$, $5.69\left(\mathrm{~s}, 2 \mathrm{H}, \mathrm{N}-\mathrm{CH}_{2}\right) .{ }^{13} \mathrm{C}-\mathrm{NMR}\left(151 \mathrm{MHz}, \mathrm{CDCl}_{3}\right): \delta=164.95(\mathrm{C}=\mathrm{O}), 162.95\left(\mathrm{~d},{ }^{1} J_{(\mathrm{CF})}=246.6 \mathrm{~Hz}, \mathrm{C}^{\prime}\right)$, $160.19,150.43,138.50\left(\mathrm{~d}^{3} \mathrm{~J}_{(\mathrm{CCCF})}=7.5 \mathrm{~Hz}, \mathrm{C} 5^{\prime}\right), 137.13,136.79,130.25\left(\mathrm{~d}, J=8.1 \mathrm{~Hz}, \mathrm{C} 1^{\prime}\right), 129.53,125.98$, $124.42,123.74\left(\mathrm{~d},{ }^{4} J_{(\mathrm{CCCCF})}=3.1 \mathrm{~Hz}, \mathrm{C6}^{\prime}\right), 120.18,116.54,115.33\left(\mathrm{~d},{ }^{2} J_{(\mathrm{CCF})}=21.0 \mathrm{~Hz}, \mathrm{C} 4^{\prime}\right), 115.14$ $\left(\mathrm{d},{ }^{2} J_{(\mathrm{CCF})}=22.0 \mathrm{~Hz}, \mathrm{C} 2^{\prime}\right), 67.77\left(\mathrm{~d},{ }^{4} J_{\mathrm{CCCCF}}=1.5 \mathrm{~Hz}, \mathrm{~N}-\mathrm{CH}_{2}\right)$. Anal. Calcd. for $\mathrm{C}_{17} \mathrm{H}_{12} \mathrm{BrFN}_{2} \mathrm{O}: \mathrm{C}$, 56.85; H, 3.37; N, 7.80. Found: C, 56.99; H, 2.97; N, 7.84.

6-Bromo-3-(4-fluorobenzyl)-2-vinylquinazolin-4(3H)-one (13h). A yellowish amorphous solid, m.p. 100-103 ${ }^{\circ} \mathrm{C}$ (re-crystallized from chloroform-petroleum ether). IR $\left(\mathrm{KBr}, \mathrm{cm}^{-1}\right) v_{\max }$ : 3064, 2926, 
1608, 1565, 1510, 1487, 1354, 1219, 1118, 989, 832, 697, 501. ${ }^{1} \mathrm{H}-\mathrm{NMR}\left(200 \mathrm{MHz}, \mathrm{CDCl}_{3}\right): \delta=8.26$ $\left(\mathrm{d},{ }^{4} J=2.1 \mathrm{~Hz}, 1 \mathrm{H}, H C 5\right), 7.85\left(\mathrm{dd},{ }^{3} J=8.9 \mathrm{~Hz},{ }^{4} J=2.1 \mathrm{~Hz}, 1 \mathrm{H}, H C 7\right), 7.75\left(\mathrm{~d},{ }^{3} J=8.9 \mathrm{~Hz}, 1 \mathrm{H}\right.$, HC8), 7.55-7.48 (m, 2H), 7.15-7.06 (m, 2H), $6.90\left(\mathrm{dd},{ }^{3} \mathrm{~J}=17.2 \mathrm{~Hz},{ }^{3} \mathrm{~J}=11.5 \mathrm{~Hz}, 1 \mathrm{H}, \mathrm{CH}=\mathrm{CH}_{2}\right), 6.72$ $\left(\mathrm{dd},{ }^{3} \mathrm{~J}=17.2 \mathrm{~Hz},{ }^{2} J=2.3 \mathrm{~Hz}, 1 \mathrm{H}, \mathrm{CH}=\mathrm{CH}_{2}\right), 5.82\left(\mathrm{dd},{ }^{3} \mathrm{~J}=11.5 \mathrm{~Hz},{ }^{2} \mathrm{~J}=2.3 \mathrm{~Hz}, 1 \mathrm{H}, \mathrm{CH}=\mathrm{CH}_{2}\right), 5.63$ $\left(\mathrm{s}, 2 \mathrm{H}, \mathrm{N}-\mathrm{CH}_{2}\right) \cdot{ }^{13} \mathrm{C}-\mathrm{NMR}\left(151 \mathrm{MHz}, \mathrm{CDCl}_{3}\right): \delta=165.04(\mathrm{C}=\mathrm{O}), 162.82\left(\mathrm{~d},{ }^{1} J_{(\mathrm{CF})}=247.1 \mathrm{~Hz}, \mathrm{C}^{\prime}\right), 160.20$, $150.40,137.04,136.88,131.84\left(\mathrm{~d},{ }^{4} J_{(\mathrm{CCCCF})}=3.1 \mathrm{~Hz}, \mathrm{C} 1^{\prime}\right), 130.39\left(\mathrm{~d},{ }^{3} J_{(\mathrm{CCCF})}=8.6 \mathrm{~Hz}, \mathrm{C} 2^{\prime}, \mathrm{C}^{\prime}\right), 129.50$, $125.99,124.28,120.08,116.60,115.62\left(\mathrm{~d},{ }^{2} J_{(\mathrm{CCF})}=21.9 \mathrm{~Hz}, \mathrm{C}^{\prime}, \mathrm{C}^{\prime}\right), 67.94\left({\left.\mathrm{~N}-\mathrm{CH}_{2}\right)}^{\prime}\right.$. Anal. Calcd. for $\mathrm{C}_{17} \mathrm{H}_{12} \mathrm{BrFN}_{2} \mathrm{O}: \mathrm{C}, 56.85 ; \mathrm{H}, 3.37 ; \mathrm{N}, 7.80$. Found: $\mathrm{C}, 56.50 ; \mathrm{H}, 3.01 ; \mathrm{N}, 7.76$.

6-Bromo-3-(2,4-difluorobenzyl)-2-vinylquinazolin-4(3H)-one (13i). A yellowish amorphous solid, m.p. 88-90 ${ }^{\circ} \mathrm{C}$ (re-crystallized from chloroform-petroleum ether). IR $\left(\mathrm{KBr}, \mathrm{cm}^{-1}\right) v_{\max }: 3079,2923,2852$, $1614,1565,1508,1488,1416,1349,1279,1099,955,834,728,538 .{ }^{1} \mathrm{H}-\mathrm{NMR}\left(600 \mathrm{MHz}, \mathrm{CDCl}_{3}\right): \delta=8.27$ $\left(\mathrm{d},{ }^{4} J=2.1 \mathrm{~Hz}, 1 \mathrm{H}, H C 5\right), 7.88\left(\mathrm{dd},{ }^{3} J=8.9 \mathrm{~Hz},{ }^{4} J=2.1 \mathrm{~Hz}, 1 \mathrm{H}, H C 7\right), 7.78\left(\mathrm{~d},{ }^{3} J=8.9 \mathrm{~Hz}, 1 \mathrm{H}\right.$, HC8), 7.59-7.55 (m, 1H), 6.96-6.89 (m, 2H), $6.89\left(\mathrm{dd},{ }^{3} \mathrm{~J}=17.2 \mathrm{~Hz},{ }^{3} \mathrm{~J}=10.0 \mathrm{~Hz}, 1 \mathrm{H}, \mathrm{CH}=\mathrm{CH}_{2}\right), 6.72$ $\left(\mathrm{dd},{ }^{3} \mathrm{~J}=17.2 \mathrm{~Hz},{ }^{2} J=2.4 \mathrm{~Hz}, 1 \mathrm{H}, \mathrm{CH}=\mathrm{CH}_{2}\right), 5.82\left(\mathrm{dd},{ }^{3} J=10.0 \mathrm{~Hz},{ }^{2} J=2.4 \mathrm{~Hz}, 1 \mathrm{H}, \mathrm{CH}=\mathrm{CH}_{2}\right)$, $5.68\left(\mathrm{~s}, 2 \mathrm{H}, \mathrm{N}-\mathrm{CH}_{2}\right) .{ }^{13} \mathrm{C}-\mathrm{NMR}\left(151 \mathrm{MHz}, \mathrm{CDCl}_{3}\right) \delta: 164.86(\mathrm{C}=\mathrm{O}), 163.23\left(\mathrm{dd},{ }^{1} J_{(\mathrm{CF})}=250.4 \mathrm{~Hz}\right.$, $\left.{ }^{3} J_{(\mathrm{CCCF})}=12.0 \mathrm{~Hz}, \mathrm{C} 2^{\prime}\right), 161.45\left(\mathrm{dd},{ }^{1} J_{(\mathrm{CF})}=251.8 \mathrm{~Hz},{ }^{3} J_{(\mathrm{CCCF})}=12.1 \mathrm{~Hz}, \mathrm{C} 4^{\prime}\right), 160.15,150.38,137.06$, $136.80,131.83\left(\mathrm{dd},{ }^{3} J_{(\mathrm{CCCF})}=9.8 \mathrm{~Hz},{ }^{3} J_{(\mathrm{CCCF})}=5.4 \mathrm{~Hz}, \mathrm{C}^{\prime}\right), 129.49,125.95,124.39,120.12,119.29$ $\left(\mathrm{dd},{ }^{2} J_{(\mathrm{CCF})}=15.0 \mathrm{~Hz},{ }^{4} J_{(\mathrm{CCCCF})}=4.0 \mathrm{~Hz}, \mathrm{Cl}^{\prime}\right), 116.48,111.50\left(\mathrm{dd},{ }^{2} J_{(\mathrm{CCF})}=21.7 \mathrm{~Hz},{ }^{4} J_{(\mathrm{CCCCF})}=4.1 \mathrm{~Hz}\right.$,

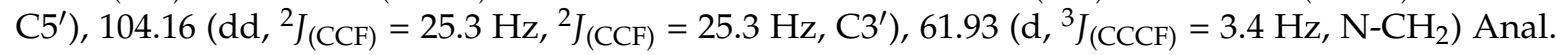
Calcd. for $\mathrm{C}_{17} \mathrm{H}_{11} \mathrm{BrF}_{2} \mathrm{~N}_{2} \mathrm{O}: \mathrm{C}, 54.13 ; \mathrm{H}, 2.94 ; \mathrm{N}, 7.43$. Found: $\mathrm{C}, 54.42 ; \mathrm{H}, 3.14 ; \mathrm{N}, 7.04$.

\subsection{General Procedure for the Synthesis of N3-Alkylated 6-bromo-2-vinyl-3H-quinazolin-4-ones 13j and 13k}

To the solution of 6-bromo-2-vinyl-3H-quinazolin-4-one $(0.251 \mathrm{~g}, 1.00 \mathrm{mmol})$ in acetonitrile $(15 \mathrm{~mL})$ potassium hydroxide $(0.168 \mathrm{~g}, 3.00 \mathrm{mmol})$ was added. After $15 \mathrm{~min}$ iodomethane $(0.124 \mathrm{~mL}, 2.00 \mathrm{mmol})$ or iodoethane $(0.088 \mathrm{~mL}, 1.10 \mathrm{mmol})$ was added and the reaction mixture was stirred at $60{ }^{\circ} \mathrm{C}$ for $5 \mathrm{~h}$. The solvent was removed and the residue was re-dissolved in methylene chloride $(10 \mathrm{~mL})$ and extracted with water $(3 \times 10 \mathrm{~mL})$. The organic layer was dried $\left(\mathrm{MgSO}_{4}\right)$, concentrated, and the crude product was purified on a silica gel column with a methylene chloride:hexane mixture $(7: 3, v / v)$ mixture followed by crystallization (chloroform:petroleum ether).

6-Bromo-3-methyl-2-vinylquinazolin-4(3H)-one (13j). A white amorphous solid, m.p. $=147-148{ }^{\circ} \mathrm{C}$ (re-crystallized from chloroform-petroleum ether). IR (KBr, cm $\left.{ }^{-1}\right) v_{\max }$ : 2956, 2924, 1675, 1661, 1555, $1468,1337,1260,1025,981,791,645 .{ }^{1} \mathrm{H}-\mathrm{NMR}\left(200 \mathrm{MHz}, \mathrm{CDCl}_{3}\right): \delta=8.21\left(\mathrm{~d},{ }^{4} J=2.1 \mathrm{~Hz}, 1 \mathrm{H}, \mathrm{HC} 5\right)$, $7.79\left(\mathrm{dd},{ }^{3} \mathrm{~J}=8.9 \mathrm{~Hz},{ }^{4} J=2.1 \mathrm{~Hz}, 1 \mathrm{H}, H \mathrm{C} 7\right), 7.67\left(\mathrm{~d},{ }^{3} \mathrm{~J}=8.9 \mathrm{~Hz}, 1 \mathrm{H}, H C 8\right), 6.83\left(\mathrm{dd},{ }^{3} J=17.2 \mathrm{~Hz}\right.$, $\left.{ }^{3} J=9.9 \mathrm{~Hz}, 1 \mathrm{H}, \mathrm{CH}=\mathrm{CH}_{2}\right), 6.66\left(\mathrm{dd}^{3} \mathrm{~J}=17.2 \mathrm{~Hz},{ }^{2} \mathrm{~J}=2.5 \mathrm{~Hz}, 1 \mathrm{H}, \mathrm{CH}=\mathrm{CH}_{2}\right), 5.74\left(\mathrm{dd},{ }^{3} \mathrm{~J}=9.9 \mathrm{~Hz}\right.$, $\left.{ }^{2} \mathrm{~J}=2.5 \mathrm{~Hz}, 1 \mathrm{H}, \mathrm{CH}=\mathrm{CH}_{2}\right), 4.14\left(\mathrm{~s}, 3 \mathrm{H}, \mathrm{CH}_{3}\right) .{ }^{13} \mathrm{C}-\mathrm{NMR}\left(151 \mathrm{MHz}, \mathrm{CDCl}_{3}\right): \delta=161.06(\mathrm{C}=\mathrm{O}), 152.56$, $146.20,137.33,129.34,129.29,128.92,127.19,121.95,120.12,30.95$. Anal. Calcd. for $\mathrm{C}_{11} \mathrm{H}_{9} \mathrm{BrN}_{2} \mathrm{O}$ : C, 49.84; H, 3.42; N, 10.57. Found: C, 50.11; H, 3.42; N, 10.56.

6-Bromo-3-ethyl-2-vinylquinazolin-4(3H)-one (13k). A white amorphous solid, m.p. $=62-64{ }^{\circ} \mathrm{C}$ (re-crystallized from chloroform-petroleum ether). IR $\left(\mathrm{KBr}, \mathrm{cm}^{-1}\right) v_{\max }$ : 3097, 3035, 2956, 2926, 2853, 1610, 1571, 1554, 1488, 1428, 1347, 1291, 1153, 1018, 842, 807, 678. ${ }^{1} \mathrm{H}-\mathrm{NMR}\left(200 \mathrm{MHz}, \mathrm{CDCl}_{3}\right)$ : $\delta=8.22\left(\mathrm{~d},{ }^{4} J=2.2 \mathrm{~Hz}, 1 \mathrm{H}, H C 5\right), 7.79\left(\mathrm{dd},{ }^{3} J=8.9 \mathrm{~Hz},{ }^{4} J=2.2 \mathrm{~Hz}, 1 \mathrm{H}, H C 7\right), 7.68\left(\mathrm{~d},{ }^{3} J=8.9 \mathrm{~Hz}\right.$, $1 \mathrm{H}, H C 8), 6.82\left(\mathrm{dd},{ }^{3} J=17.2 \mathrm{~Hz},{ }^{3} J=10.0 \mathrm{~Hz}, 1 \mathrm{H}, \mathrm{CH}=\mathrm{CH}_{2}\right), 6.63\left(\mathrm{dd},{ }^{3} J=17.2 \mathrm{~Hz},{ }^{2} J=2.4 \mathrm{~Hz}, 1 \mathrm{H}\right.$, $\left.\mathrm{CH}=\mathrm{CH}_{2}\right), 5.73\left(\mathrm{dd},{ }^{3} \mathrm{~J}=10.0 \mathrm{~Hz},{ }^{2} \mathrm{~J}=2.4 \mathrm{~Hz}, 1 \mathrm{H}, \mathrm{CH}=\mathrm{CH}_{2}\right), 4.62\left(\mathrm{q},{ }^{3} \mathrm{~J}=7.1 \mathrm{~Hz}, 2 \mathrm{H}, \mathrm{CH}_{3} \mathrm{CH}_{2}\right), 1.47$ $\left(\mathrm{t},{ }^{3} \mathrm{~J}=7.1 \mathrm{~Hz}, 3 \mathrm{H}, \mathrm{CH}_{3} \mathrm{CH}_{2}\right) .{ }^{13} \mathrm{C}-\mathrm{NMR}\left(151 \mathrm{MHz}, \mathrm{CDCl}_{3}\right): \delta=161.06(\mathrm{C}=\mathrm{O}), 160.37,150.12,136.90$, $136.78,129.34,126.10,124.19,119.83,116.71,63.10,14.28$. Anal. Calcd. for $\mathrm{C}_{12} \mathrm{H}_{11} \mathrm{BrN}_{2} \mathrm{O}: \mathrm{C}, 51.63 ; \mathrm{H}$, 3.97; N, 10.04. Found: C, 51.94; H, 3.75; N, 9.94 . 


\subsection{General Procedure for the Synthesis of Isoxazolidines trans-11 and cis-11}

A solution of the nitrone $(0.195 \mathrm{~g}, 1.00 \mathrm{mmol})$ and the respective 6-bromo-2-vinylquinazolin-4(3H)-one $(1.00 \mathrm{mmol})$ in toluene $(2 \mathrm{~mL})$ was stirred at $70{ }^{\circ} \mathrm{C}$ until the disappearance (TLC) of the starting nitrone. Solvents were evaporated in vacuo and crude products were subjected to chromatography on silica gel columns with chloroform:methanol (100:1, 50:1, 20:1, v/v) mixtures.

Diethyl trans-[5-(6-bromo-4-oxo-3,4-dihydroquinazolin-2-yl)-2-methylisoxazolidin-3-yl]phosphonate (trans-11a). Colorless oil. IR (film, $\mathrm{cm}^{-1}$ ) $v_{\text {max }}$ : 3316, 3171, 3090, 2980, 2974, 2783, 1660, 1625, 1486, 1412, 1301, 1234, $1054,968,834,775,575 .{ }^{1} \mathrm{H}-\mathrm{NMR}\left(600 \mathrm{MHz}, \mathrm{CDCl}_{3}\right): \delta=10.63(\mathrm{~s}, 1 \mathrm{H}, \mathrm{NH}), 8.44\left(\mathrm{~d},{ }^{4} \mathrm{~J}=2.3 \mathrm{~Hz}, 1 \mathrm{H}, \mathrm{HC}^{\prime}\right)$, $7.84\left(\mathrm{dd},{ }^{3} J=8.6 \mathrm{~Hz},{ }^{4} J=2.3 \mathrm{~Hz}, 1 \mathrm{H}, H C 7^{\prime}\right), 7.54\left(\mathrm{~d},{ }^{3} J=8.6 \mathrm{~Hz}, 1 \mathrm{H}, \mathrm{HC} 8^{\prime}\right), 5.02\left(\mathrm{dd},{ }^{3} J_{(\mathrm{H} 5-\mathrm{H} 4 \beta)}=8.4 \mathrm{~Hz}\right.$, $\left.{ }^{3} J_{(\mathrm{H} 5-\mathrm{H} 4 \alpha)}=6.2 \mathrm{~Hz}, 1 \mathrm{H}, \mathrm{HC} 5\right), 4.30-4.21\left(\mathrm{~m}, 4 \mathrm{H}, 2 \times \mathrm{CH}_{2} \mathrm{OP}\right), 3.25-3.21(\mathrm{~m}, 1 \mathrm{H}, \mathrm{HC} 3), 3.04\left(\mathrm{~s}, 3 \mathrm{H}, \mathrm{CH}_{3} \mathrm{~N}\right)$, $3.12\left(\mathrm{dddd},{ }^{3} J_{(\mathrm{H} 4 \beta-\mathrm{P})}=16.7 \mathrm{~Hz},{ }^{2} J_{(\mathrm{H} 4 \beta-\mathrm{H} 4 \alpha)}=12.9 \mathrm{~Hz},{ }^{3} J_{(\mathrm{H} 4 \beta-\mathrm{H} 5)}=8.6 \mathrm{~Hz},{ }^{3} J_{(\mathrm{H} 4 \beta-\mathrm{H} 3)}=8.3 \mathrm{~Hz}, 1 \mathrm{H}\right.$, $\left.H_{\beta} \mathrm{C} 4\right), 2.94\left(\mathrm{dddd},{ }^{3} J_{(\mathrm{H} 4 \alpha-\mathrm{P})}=12.9 \mathrm{~Hz},{ }^{2} J_{(\mathrm{H} 4 \alpha-\mathrm{H} 4 \beta)}=12.9 \mathrm{~Hz},{ }^{3} J_{(\mathrm{H} 4 \alpha-\mathrm{H} 3)}=10.0 \mathrm{~Hz},{ }^{3} J_{(\mathrm{H} 4 \alpha-\mathrm{H} 5)}=6.2 \mathrm{~Hz}\right.$, $\left.1 \mathrm{H}, \mathrm{H}_{\alpha} \mathrm{C} 4\right), 1.40\left(\mathrm{t},{ }^{3} \mathrm{~J}=7.1 \mathrm{~Hz}, 3 \mathrm{H}, \mathrm{CH}_{3} \mathrm{CH}_{2} \mathrm{OP}\right), 1.38\left(\mathrm{t},{ }^{3} \mathrm{~J}=7.0 \mathrm{~Hz}, 3 \mathrm{H}, \mathrm{CH}_{3} \mathrm{CH}_{2} \mathrm{OP}\right) .{ }^{13} \mathrm{C}-\mathrm{NMR}$ $\left(151 \mathrm{MHz}, \mathrm{CDCl}_{3}\right): \delta=160.30(\mathrm{C}=\mathrm{O}), 156.50,147.35,137.66,129.26,128.96,123.27,120.46,74.68$ $\left(\mathrm{d},{ }^{3} J_{(\mathrm{CCCP})}=8.6 \mathrm{~Hz}, \mathrm{C} 5\right), 64.60\left(\mathrm{~d},{ }^{1} J_{(\mathrm{CP})}=168.1 \mathrm{~Hz}, \mathrm{C} 3\right), 63.51\left(\mathrm{~d},{ }^{2} J_{(\mathrm{COP})}=6.6 \mathrm{~Hz}, \mathrm{CH}_{2} \mathrm{OP}\right), 62.61$ $\left(\mathrm{d},{ }^{2} J_{(\mathrm{COP})}=6.9 \mathrm{~Hz}, \mathrm{CH}_{2} \mathrm{OP}\right), 46.07\left(\mathrm{CH}_{3} \mathrm{~N}\right), 40.92(\mathrm{C} 4), 16.55\left(\mathrm{~d},{ }^{3} J_{(\mathrm{CCOP})}=6.2 \mathrm{~Hz}, \mathrm{CH}_{3} \mathrm{CH}_{2} \mathrm{OP}\right)$, $16.48\left(\mathrm{~d},{ }^{3} J_{(\mathrm{CCOP})}=5.5 \mathrm{~Hz}, \mathrm{CH}_{3} \mathrm{CH}_{2} \mathrm{OP}\right) .{ }^{31} \mathrm{P}-\mathrm{NMR}\left(243 \mathrm{MHz}, \mathrm{CDCl}_{3}\right): \delta=20.51$. Anal. Calcd for $\mathrm{C}_{16} \mathrm{H}_{21} \mathrm{BrN}_{3} \mathrm{O}_{5} \mathrm{P}: \mathrm{C}, 43.07 ; \mathrm{H}, 4.74 ; \mathrm{N}, 9.42$. Found: $\mathrm{C}, 43.09 ; \mathrm{H}, 4.52 ; \mathrm{N}, 9.35$.

Diethyl cis-[5-(6-bromo-4-oxo-3,4-dihydroquinazolin-2-yl)-2-methylisoxazolidin-3-yl]phosphonate (cis-11a). Colorless oil. IR (film, $\mathrm{cm}^{-1}$ ) $v_{\max }$ : 3090, 2959, 2925, 2865, 1661, 1626, 1601, 1461, 1336, 1234, 1054, 969, 834, 575. ${ }^{1} \mathrm{H}-\mathrm{NMR}\left(600 \mathrm{MHz}, \mathrm{CDCl}_{3}\right): \delta=10.63(\mathrm{~s}, 1 \mathrm{H}, \mathrm{NH}), 8.44\left(\mathrm{~d},{ }^{4} J=2.3 \mathrm{~Hz}, 1 \mathrm{H}\right.$, $\left.H C 5^{\prime}\right), 7.84\left(\mathrm{dd},{ }^{3} J=8.6 \mathrm{~Hz},{ }^{4} J=2.3 \mathrm{~Hz}, 1 \mathrm{H}, H C 7^{\prime}\right), 7.54\left(\mathrm{~d}^{3}{ }^{3} \mathrm{~J}=8.6 \mathrm{~Hz}, 1 \mathrm{H}, H C 8^{\prime}\right), 5.07(\mathrm{dd}$, $\left.{ }^{3} J_{(\mathrm{H} 5-\mathrm{H} 4 \alpha)}=9.2 \mathrm{~Hz},{ }^{3} J_{(\mathrm{H} 5-\mathrm{H} 4 \beta)}=4.3 \mathrm{~Hz}, 1 \mathrm{H}, \mathrm{HC} 5\right), 4.23-4.12\left(\mathrm{~m}, 4 \mathrm{H}, 2 \times \mathrm{CH}_{2} \mathrm{OP}\right), 3.21(\mathrm{dddd}$, $\left.{ }^{3} J_{(\mathrm{H} 4 \beta-\mathrm{P})}=19.8 \mathrm{~Hz},{ }^{2} J_{(\mathrm{H} 4 \beta-\mathrm{H} 4 \alpha)}=10.9 \mathrm{~Hz},{ }^{3} J_{(\mathrm{H} 4 \beta-\mathrm{H} 3)}=6.8 \mathrm{~Hz},{ }^{3} J_{(\mathrm{H} 4 \beta-\mathrm{H} 5)}=4.3 \mathrm{~Hz}, 1 \mathrm{H}, H_{\beta} \mathrm{C} 4\right), 3.12$ $\left(\mathrm{ddd},{ }^{3} J_{(\mathrm{H} 3-\mathrm{H} 4 \beta)}=6.8 \mathrm{~Hz},{ }^{3} J_{(\mathrm{H} 3-\mathrm{H} 4 \alpha)}=9.6 \mathrm{~Hz},{ }^{2} J_{(\mathrm{H} 3-\mathrm{P})}=4.4 \mathrm{~Hz} 1 \mathrm{H}, \mathrm{HC} 3\right), 3.00\left(\mathrm{~s}, 3 \mathrm{H}, \mathrm{CH}_{3} \mathrm{~N}\right), 2.83$ $\left(\mathrm{dddd},{ }^{3} J_{(\mathrm{H} 4 \alpha-\mathrm{P})}=13.1 \mathrm{~Hz},{ }^{2} J_{(\mathrm{H} 4 \alpha-\mathrm{H} 4 \beta)}=10.9 \mathrm{~Hz},{ }^{3} J_{(\mathrm{H} 4 \alpha-\mathrm{H} 3)}=9.6 \mathrm{~Hz},{ }^{3} J_{(\mathrm{H} 4 \alpha-\mathrm{H} 5)}=9.2 \mathrm{~Hz}, 1 \mathrm{H}, H_{\alpha} \mathrm{C} 4\right)$, $1.32\left(\mathrm{t},{ }^{3} \mathrm{~J}=7.0 \mathrm{~Hz}, 3 \mathrm{H}, \mathrm{CH}_{3} \mathrm{CH}_{2} \mathrm{OP}\right), 1.27\left(\mathrm{t},{ }^{3} \mathrm{~J}=7.1 \mathrm{~Hz}, 3 \mathrm{H}, \mathrm{CH}_{3} \mathrm{CH}_{2} \mathrm{OP}\right) .{ }^{13} \mathrm{C}-\mathrm{NMR}\left(151 \mathrm{MHz}, \mathrm{CDCl}_{3}\right)$ : $\delta=160.33(\mathrm{C}=\mathrm{O}), 156.50,147.35,137.65,129.26,128.96,123.27,120.46,75.58\left(\mathrm{~d},{ }^{3} J_{(\mathrm{CCCP})}=6.6 \mathrm{~Hz}\right.$, C5), $63.58\left(\mathrm{~d},{ }^{1} J_{(\mathrm{CP})}=169.1 \mathrm{~Hz}, \mathrm{C} 3\right), 63.18\left(\mathrm{~d},{ }^{2} J_{(\mathrm{COP})}=6.5 \mathrm{~Hz}, \mathrm{CH}_{2} \mathrm{OP}\right), 63.15\left(\mathrm{~d},{ }^{2} J_{(\mathrm{COP})}=6.4 \mathrm{~Hz}\right.$, $\left.\mathrm{CH}_{2} \mathrm{OP}\right), 45.58\left(\mathrm{~d},{ }^{3} J_{(\mathrm{CNCP})}=5.8 \mathrm{~Hz}, \mathrm{CH}_{3} \mathrm{~N}\right), 37.71(\mathrm{C} 4), 16.38\left(\mathrm{~d},{ }^{3} \mathrm{~J}_{(\mathrm{CCOP})}=5.3 \mathrm{~Hz}, \mathrm{CH}_{3} \mathrm{CH}_{2} \mathrm{OP}\right)$, $16.37\left(\mathrm{~d},{ }^{3} J_{(\mathrm{CCOP})}=5.4 \mathrm{~Hz}, \mathrm{CH}_{3} \mathrm{CH}_{2} \mathrm{OP}\right) .{ }^{31} \mathrm{P}-\mathrm{NMR}\left(243 \mathrm{MHz}, \mathrm{CDCl}_{3}\right): \delta=20.92$. Anal. Calcd. for $\mathrm{C}_{16} \mathrm{H}_{21} \mathrm{BrN}_{3} \mathrm{O}_{5} \mathrm{P}: \mathrm{C}, 43.07 ; \mathrm{H}, 4.74 ; \mathrm{N}, 9.42$. Found: $\mathrm{C}, 43.12 ; \mathrm{H}, 4.35 ; \mathrm{N}, 9.33$.

Diethyl trans-[5-(3-benzyl-6-bromo-4-oxo-3,4-dihydroquinazolin-2-yl)-2-methylisoxazolidin-3-yl]phosphonate (trans-11b). A yellowish oil. IR (film, $\mathrm{cm}^{-1}$ ) $v_{\max }$ : 3040, 2980, 2926, 2853, 1613, 1568, 1490, 1418, 1353, 1239, 1056, 1025, 835, 822, 699. ${ }^{1} \mathrm{H}-\mathrm{NMR}\left(600 \mathrm{MHz}, \mathrm{CDCl}_{3}\right): \delta=8.33\left(\mathrm{~d},{ }^{4} \mathrm{~J}=2.3 \mathrm{~Hz}, 1 \mathrm{H}, H C 5^{\prime}\right), 7.90(\mathrm{dd}$, $\left.{ }^{3} J=8.9 \mathrm{~Hz},{ }^{4} J=2.3 \mathrm{~Hz}, 1 \mathrm{H}, H C 7^{\prime}\right), 7.83\left(\mathrm{~d}^{3}{ }^{3} J=8.9 \mathrm{~Hz}, 1 \mathrm{H}, H C 8^{\prime}\right), 7.55-7.53(\mathrm{~m}, 2 \mathrm{H}), 7.45-7.42(\mathrm{~m}, 2 \mathrm{H})$, $7.40-7.37(\mathrm{~m}, 1 \mathrm{H}), 5.66\left(\mathrm{~s}, 2 \mathrm{H}, \mathrm{N}-\mathrm{CH}_{2}\right), 5.25\left(\mathrm{dd},{ }^{3} J_{(\mathrm{H} 5-\mathrm{H} 4 \beta)}=6.8 \mathrm{~Hz}^{3}{ }^{3} J_{(\mathrm{H} 5-\mathrm{H} 4 \alpha)}=6.4 \mathrm{~Hz}, 1 \mathrm{H}, \mathrm{HC} 5\right), 4.33-4.19$ (m, 4H, $\left.2 \times \mathrm{CH}_{2} \mathrm{OP}\right), 3.42-3.39(\mathrm{~m}, 1 \mathrm{H}, \mathrm{HC} 3), 3.07-2.94\left(\mathrm{~m}, 2 \mathrm{H}, \mathrm{H}_{\alpha} \mathrm{C} 4, \mathrm{H}_{\beta} \mathrm{C} 4\right), 3.05\left(\mathrm{~s}, 3 \mathrm{H}, \mathrm{CH}_{3} \mathrm{~N}\right), 1.42$ $\left(\mathrm{t},{ }^{3} \mathrm{~J}=7.0 \mathrm{~Hz}, 3 \mathrm{H}, \mathrm{CH}_{3} \mathrm{CH}_{2} \mathrm{OP}\right), 1.39\left(\mathrm{t},{ }^{3} \mathrm{~J}=6.9 \mathrm{~Hz}, 3 \mathrm{H}, \mathrm{CH}_{3} \mathrm{CH}_{2} \mathrm{OP}\right) .{ }^{13} \mathrm{C}-\mathrm{NMR}\left(151 \mathrm{MHz}, \mathrm{CDCl}_{3}\right)$ : $\delta=166.08(\mathrm{C}=\mathrm{O}), 163.35,149.91,137.20,135.69,129.67,128.67,128.65,128.52,128.45,125.97,120.69,80.15$ $\left(\mathrm{d},{ }^{3} J_{(\mathrm{CCCP})}=8.5 \mathrm{~Hz}, \mathrm{C} 5\right), 69.14\left(\mathrm{~N}_{-C_{2}}\right), 64.41\left(\mathrm{~d},{ }^{1} J_{(\mathrm{CP})}=168.8 \mathrm{~Hz}, \mathrm{C} 3\right), 63.26\left(\mathrm{~d},{ }^{2} J_{(\mathrm{COP})}=6.5 \mathrm{~Hz}, \mathrm{CH}_{2} \mathrm{OP}\right)$, $62.42\left(\mathrm{~d},{ }^{2} J_{(\mathrm{COP})}=7.2 \mathrm{~Hz}, \mathrm{CH}_{2} \mathrm{OP}\right), 46.62\left(\mathrm{CH}_{3} \mathrm{~N}\right), 37.90(\mathrm{C} 4), 16.58\left(\mathrm{~d},{ }^{3} J_{(\mathrm{CCOP})}=5.6 \mathrm{~Hz}, \mathrm{CH}_{3} \mathrm{CH}_{2} \mathrm{OP}\right)$, $16.52\left(\mathrm{~d},{ }^{3} J_{(\mathrm{CCOP})}=5.6 \mathrm{~Hz}, \mathrm{CH}_{3} \mathrm{CH}_{2} \mathrm{OP}\right) .{ }^{31} \mathrm{P}-\mathrm{NMR}\left(243 \mathrm{MHz}, \mathrm{CDCl}_{3}\right): \delta=22.04$. Anal. Calcd. for $\mathrm{C}_{23} \mathrm{H}_{27} \mathrm{BrN}_{3} \mathrm{O}_{5} \mathrm{P}: \mathrm{C}, 51.50 ; \mathrm{H}, 5.07 ; \mathrm{N}, 7.83$. Found: $\mathrm{C}, 51.78 ; \mathrm{H}, 5.11 ; \mathrm{N}, 7.70$.

Diethyl trans-\{5-[6-bromo-3-(2-nitrobenzyl)-4-oxo-3,4-dihydroquinazolin-2-yl]-2-methylisoxazolidin-3-yl\}phosphonate (trans-11c). A yellowish oil. IR (film, $\mathrm{cm}^{-1}$ ) $v_{\max }: 3444,3077,2979,2925,2853,1690,1614,1575,1527$, $1489,1413,1355,1337,1055,1024,835,791,730,574 .{ }^{1} \mathrm{H}-\mathrm{NMR}\left(600 \mathrm{MHz}, \mathrm{CDCl}_{3}\right): \delta=8.36\left(\mathrm{~d},{ }^{4} \mathrm{~J}=2.0 \mathrm{~Hz}\right.$, $\left.1 \mathrm{H}, H C 5^{\prime}\right), 8.20-8.18(\mathrm{~m}, 1 \mathrm{H}), 7.95\left(\mathrm{dd},{ }^{3} J=8.9 \mathrm{~Hz},{ }^{4} J=2.3 \mathrm{~Hz}, 1 \mathrm{H}, H C 7^{\prime}\right), 7.87\left(\mathrm{~d},{ }^{4} J=8.9 \mathrm{~Hz}\right.$, 
$\left.1 \mathrm{H}, H C 8^{\prime}\right), 7.78-7.76(\mathrm{~m}, 1 \mathrm{H}), 7.72-7.69(\mathrm{~m}, 1 \mathrm{H}), 7.57-7.55(\mathrm{~m}, 1 \mathrm{H}), 6.10\left(\mathrm{AB}, J_{\mathrm{AB}}=14.6 \mathrm{~Hz}, 1 \mathrm{H}\right.$, $\left.\mathrm{N}-\mathrm{CH}_{2 \mathrm{~b}}\right), 6.07\left(\mathrm{AB}, J_{\mathrm{AB}}=14.6 \mathrm{~Hz}, 1 \mathrm{H}, \mathrm{N}-\mathrm{CH}_{2 \mathrm{a}}\right), 5.21\left(\mathrm{dd},{ }^{3} J_{(\mathrm{H} 5-\mathrm{H} 4 \beta)}=8.0 \mathrm{~Hz},{ }^{3} J_{(\mathrm{H} 5-\mathrm{H} 4 \alpha)}=6.1 \mathrm{~Hz}\right.$, 1H, HC5), 4.31-4.22 (m, 4H, $\left.2 \times \mathrm{CH}_{2} \mathrm{OP}\right), 3.36-3.33(\mathrm{~m}, 1 \mathrm{H}, \mathrm{HC} 3), 3.00\left(\mathrm{~s}, 3 \mathrm{H}, \mathrm{CH}_{3} \mathrm{~N}\right), 2.99$ $\left(\mathrm{dddd},{ }^{2} J_{(\mathrm{H} 4 \beta-\mathrm{P})}=16.6 \mathrm{~Hz},{ }^{3} J_{(\mathrm{H} 4 \beta-\mathrm{H} 4 \alpha)}=12.6 \mathrm{~Hz},{ }^{3} J_{(\mathrm{H} 4 \beta-\mathrm{H} 3)}=8.2 \mathrm{~Hz},{ }^{3} J_{(\mathrm{H} 4 \beta-\mathrm{H} 5)}=8.0 \mathrm{~Hz}, 1 \mathrm{H}, H_{\beta} \mathrm{C} 4\right)$, $2.38\left(\mathrm{dddd},{ }^{2} J_{(\mathrm{H} 4 \alpha-\mathrm{H} 4 \beta)}=12.6 \mathrm{~Hz},{ }^{3} J_{(\mathrm{H} 4 \alpha-\mathrm{P})}=10.2 \mathrm{~Hz},{ }^{3} J_{(\mathrm{H} 4 \alpha-\mathrm{H} 3)}=8.8 \mathrm{~Hz},{ }^{3} J_{(\mathrm{H} 4 \alpha-\mathrm{H} 5)}=6.1 \mathrm{~Hz}, 1 \mathrm{H}\right.$, $\left.\mathrm{H}_{\alpha} \mathrm{C} 4\right), 1.41\left(\mathrm{t},{ }^{3} \mathrm{~J}=7.1 \mathrm{~Hz}, 3 \mathrm{H}, \mathrm{CH}_{3} \mathrm{CH}_{2} \mathrm{OP}\right), 1.39\left(\mathrm{t},{ }^{3} \mathrm{~J}=7.1 \mathrm{~Hz}, 3 \mathrm{H}, \mathrm{CH}_{3} \mathrm{CH}_{2} \mathrm{OP}\right) .{ }^{13} \mathrm{C}-\mathrm{NMR}(151 \mathrm{MHz}$, $\left.\mathrm{CDCl}_{3}\right): \delta=165.56(\mathrm{C}=\mathrm{O}), 163.42,150.09,147.81,137.49,133.80,132.03,129.85,129.14,129.00,125.66$, $125.15,121.03,116.40,80.08\left(\mathrm{~d},{ }^{3} J_{(\mathrm{CCCP})}=7.8 \mathrm{~Hz}, \mathrm{C} 5\right), 65.64\left(\mathrm{~N}_{-C_{2}}\right), 64.30\left(\mathrm{~d},{ }^{1} J_{(\mathrm{CP})}=168.5 \mathrm{~Hz}, \mathrm{C} 3\right)$, $63.21\left(\mathrm{~d},{ }^{2} J_{(\mathrm{COP})}=6.3 \mathrm{~Hz}, \mathrm{CH}_{2} \mathrm{OP}\right), 62.49\left(\mathrm{~d},{ }^{2} J_{(\mathrm{COP})}=6.8 \mathrm{~Hz}, \mathrm{CH}_{2} \mathrm{OP}\right), 46.61\left(\mathrm{~d},{ }^{3} J_{(\mathrm{CNCP})}=4.2 \mathrm{~Hz}\right.$, $\left.\mathrm{CH}_{3} \mathrm{~N}\right), 37.91(\mathrm{C} 4), 16.54\left(\mathrm{~d},{ }^{3} J_{(\mathrm{CCOP})}=5.6 \mathrm{~Hz}, \mathrm{CH}_{3} \mathrm{CH}_{2} \mathrm{OP}\right), 16.49\left(\mathrm{~d},{ }^{3} J_{(\mathrm{CCOP})}=5.5 \mathrm{~Hz}, \mathrm{CH}_{3} \mathrm{CH}_{2} \mathrm{OP}\right)$. ${ }^{31} \mathrm{P}-\mathrm{NMR}\left(243 \mathrm{MHz}, \mathrm{CDCl}_{3}\right): \delta=21.85$. Anal. Calcd. for $\mathrm{C}_{23} \mathrm{H}_{26} \mathrm{BrN}_{4} \mathrm{O}_{7} \mathrm{P}: \mathrm{C}, 47.52 ; \mathrm{H}, 4.51 ; \mathrm{N}, 9.64$. Found: $\mathrm{C}, 47.22 ; \mathrm{H}, 4.40 ; \mathrm{N}, 9.35$.

Diethyl trans-\{5-[6-bromo-3-(3-nitrobenzyl)-4-oxo-3,4-dihydroquinazolin-2-yl]-2-methylisoxazolidin-3-yl\}phosphonate (trans-11d). A yellowish oil. IR (film, $\mathrm{cm}^{-1}$ ) $v_{\max }$ : 3078, 2980, 2926, 2854, 1613, 1566, 1531, 1489, $1416,1348,1242,1115,1053,1024,966,836,805,733,671 .{ }^{1} \mathrm{H}-\mathrm{NMR}\left(600 \mathrm{MHz}, \mathrm{CDCl}_{3}\right): \delta=8.44-8.42$ $(\mathrm{m}, 1 \mathrm{H}), 8.32\left(\mathrm{~d},{ }^{4} J=2.0 \mathrm{~Hz}, 1 \mathrm{H}, H C 5^{\prime}\right), 8.24-8.22(\mathrm{~m}, 1 \mathrm{H}), 7.92\left(\mathrm{dd},{ }^{3} J=8.9 \mathrm{~Hz},{ }^{4} J=2.0 \mathrm{~Hz}, 1 \mathrm{H}\right.$, $\left.H C 7^{\prime}\right), 7.90-7.88(\mathrm{~m}, 1 \mathrm{H}), 7.84\left(\mathrm{~d}^{3} \mathrm{~J}=8.9 \mathrm{~Hz}, 1 \mathrm{H}, H C 8^{\prime}\right), 7.63-7.60(\mathrm{~m}, 1 \mathrm{H}), 5.77\left(\mathrm{~s}, 2 \mathrm{H}, \mathrm{N}-\mathrm{CH}_{2}\right), 5.29$ $\left(\mathrm{dd},{ }^{3} J_{(\mathrm{H} 5-\mathrm{H} 4 \beta)}=8.0 \mathrm{~Hz},{ }^{3} J_{(\mathrm{H} 5-\mathrm{H} 4 \alpha)}=6.4 \mathrm{~Hz}, 1 \mathrm{H}, \mathrm{HC} 5\right), 4.34-4.23\left(\mathrm{~m}, 4 \mathrm{H}, 2 \times \mathrm{CH}_{2} \mathrm{OP}\right), 3.44-3.37(\mathrm{~m}$, $1 \mathrm{H}, \mathrm{HC} 3), 3.10-2.94\left(\mathrm{~m}, 2 \mathrm{H}, \mathrm{H}_{\alpha} \mathrm{C} 4, \mathrm{H}_{\beta} \mathrm{C} 4\right), 3.07\left(\mathrm{~s}, 3 \mathrm{H}, \mathrm{CH}_{3} \mathrm{~N}\right), 1.43\left(\mathrm{t},{ }^{3} \mathrm{~J}=7.1 \mathrm{~Hz}, 3 \mathrm{H}, \mathrm{CH}_{3} \mathrm{CH}_{2} \mathrm{OP}\right)$, $1.41\left(\mathrm{t},{ }^{3} \mathrm{~J}=7.0 \mathrm{~Hz}, 3 \mathrm{H}, \mathrm{CH}_{3} \mathrm{CH}_{2} \mathrm{OP}\right) .{ }^{13} \mathrm{C}-\mathrm{NMR}\left(151 \mathrm{MHz}, \mathrm{CDCl}_{3}\right): \delta=165.59(\mathrm{C}=\mathrm{O}), 163.05$, $150.03,148.49,137.81,137.49,134.31,129.78,129.76,125.74,123.45,123.29,121.03,116.42,80.00(\mathrm{~d}$, $\left.{ }^{3} J_{(\mathrm{CCCP})}=8.4 \mathrm{~Hz}, \mathrm{C} 5\right), 65.61\left(\mathrm{~N}-\mathrm{CH}_{2}\right), 64.38\left(\mathrm{~d},{ }^{1} J_{(\mathrm{CP})}=168.5 \mathrm{~Hz}, \mathrm{C} 3\right), 63.26\left(\mathrm{~d},{ }^{2} J_{(\mathrm{COP})}=6.5 \mathrm{~Hz}\right.$, $\left.\mathrm{CH}_{2} \mathrm{OP}\right), 62.50\left(\mathrm{~d},{ }^{2} J_{(\mathrm{COP})}=6.8 \mathrm{~Hz}, \mathrm{CH}_{2} \mathrm{OP}\right), 46.57\left(\mathrm{CH}_{3} \mathrm{~N}\right), 37.77(\mathrm{C} 4), 16.56\left(\mathrm{~d},{ }^{3} J_{(\mathrm{CCOP})}=5.6 \mathrm{~Hz}\right.$, $\left.\mathrm{CH}_{3} \mathrm{CH}_{2} \mathrm{OP}\right), 16.50\left(\mathrm{~d},{ }^{3} J_{(\mathrm{CCOP})}=5.9 \mathrm{~Hz}, \mathrm{CH}_{3} \mathrm{CH}_{2} \mathrm{OP}\right) .{ }^{31} \mathrm{P}-\mathrm{NMR}\left(243 \mathrm{MHz}, \mathrm{CDCl}_{3}\right): \delta=21.52$. Anal. Calcd. for $\mathrm{C}_{23} \mathrm{H}_{26} \mathrm{BrN}_{4} \mathrm{O}_{7} \mathrm{P}: \mathrm{C}, 47.52 ; \mathrm{H}, 4.51 ; \mathrm{N}$, 9.64. Found: $\mathrm{C}, 47.71 ; \mathrm{H}, 4.51 ; \mathrm{N}, 9.44$.

Diethyl trans-\{5-[6-bromo-3-(4-nitrobenzyl)-4-oxo-3,4-dihydroquinazolin-2-yl]-2-methylisoxazolidin-3-yl\}phosphonate (trans-11e). A yellowish oil. IR (film, $\mathrm{cm}^{-1}$ ) $v_{\max }$ : 3069, 2969, 2925, 2854, 1610, 1571, 1523, 1490, $1343,1285,1241,1114,1027,968,837 .{ }^{1} \mathrm{H}-\mathrm{NMR}\left(600 \mathrm{MHz}, \mathrm{CDCl}_{3}\right): \delta=8.35\left(\mathrm{~d},{ }^{4} \mathrm{~J}=2.0 \mathrm{~Hz}, 1 \mathrm{H}\right.$, $\left.\left.H C 5^{\prime}\right), 1 \mathrm{H}\right), 8.30-8.28(\mathrm{~m}, 2 \mathrm{H}), 7.95\left(\mathrm{dd},{ }^{3} J=8.9 \mathrm{~Hz},{ }^{4} J=2.0 \mathrm{~Hz}, 1 \mathrm{H}, H C 7^{\prime}\right), 7.86\left(\mathrm{~d},{ }^{3} J=8.9 \mathrm{~Hz}, 1 \mathrm{H}\right.$, $\left.H C 8^{\prime}\right), 7.72-7.71(\mathrm{~m}, 2 \mathrm{H}), 5.76\left(\mathrm{~s}, 1 \mathrm{H}, \mathrm{N}-\mathrm{CH}_{2}\right), 5.24\left(\mathrm{dd},{ }^{3} J_{(\mathrm{H} 5-\mathrm{H} 4 \beta)}=6.4 \mathrm{~Hz},{ }^{3} J_{(\mathrm{H} 5-\mathrm{H} 4 \alpha)}=6.0 \mathrm{~Hz}, 1 \mathrm{H}\right.$, HC5), 4.32-4.22 (m, 4H, $\left.2 \times \mathrm{CH}_{2} \mathrm{OP}\right), 3.37-3.33(\mathrm{~m}, 1 \mathrm{H}, \mathrm{HC} 3), 3.07-2.98\left(\mathrm{~m}, 1 \mathrm{H}, \mathrm{H}_{\beta} \mathrm{C} 4\right), 3.03(\mathrm{~s}, 3 \mathrm{H}$, $\left.\mathrm{CH}_{3}-\mathrm{N}\right), 2.94\left(\mathrm{dddd},{ }^{3} J_{(\mathrm{H} 4 \alpha-\mathrm{P})}=12.4 \mathrm{~Hz},{ }^{2} J_{(\mathrm{H} 4 \alpha-\mathrm{H} 4 \beta)}=12.4 \mathrm{~Hz},{ }^{3} J_{(\mathrm{H} 4 \alpha-\mathrm{H} 3)}=9.2 \mathrm{~Hz},{ }^{3} J_{(\mathrm{H} 4 \alpha-\mathrm{H} 5)}=6.0 \mathrm{~Hz}\right.$, $\left.1 \mathrm{H}, \mathrm{H}_{\alpha} \mathrm{C} 4\right), 1.41\left(\mathrm{t},{ }^{3} \mathrm{~J}=7.0 \mathrm{~Hz}, 3 \mathrm{H}, \mathrm{CH}_{3} \mathrm{CH}_{2} \mathrm{OP}\right), 1.39\left(\mathrm{t},{ }^{3} \mathrm{~J}=7.0 \mathrm{~Hz}, 3 \mathrm{H}, \mathrm{CH}_{3} \mathrm{CH}_{2} \mathrm{OP}\right) .{ }^{13} \mathrm{C}-\mathrm{NMR}$ $\left(151 \mathrm{MHz}, \mathrm{CDCl}_{3}\right): \delta=165.57(\mathrm{C}=\mathrm{O}), 163.06,150.04,147.95,142.93,137.55,129.83,128.67,125.69,123.92$, $121.09,116.42,79.97\left(\mathrm{~d},{ }^{3} J_{(\mathrm{CCCP})}=8.6 \mathrm{~Hz}, \mathrm{C} 5\right), 67.55\left(\mathrm{~s}, \mathrm{~N}-\mathrm{CH}_{2}\right), 64.40\left(\mathrm{~d},{ }^{1} J_{(\mathrm{CP})}=168.3 \mathrm{~Hz}, \mathrm{C} 3\right), 63.28$ $\left(\mathrm{d},{ }^{2} J_{(\mathrm{COP})}=6.5 \mathrm{~Hz}, \mathrm{CH}_{2} \mathrm{OP}\right), 62.46\left(\mathrm{~d},{ }^{2} J_{(\mathrm{COP})}=7.1 \mathrm{~Hz}, \mathrm{CH}_{2} \mathrm{OP}\right), 46.55\left(\mathrm{CH}_{3} \mathrm{~N}\right), 37.77(\mathrm{C} 4), 16.56(\mathrm{~d}$, $\left.{ }^{3} J_{(\mathrm{CCOP})}=5.7 \mathrm{~Hz}, \mathrm{CH}_{3} \mathrm{CH}_{2} \mathrm{OP}\right), 16.50\left(\mathrm{~d},{ }^{3} J_{(\mathrm{CCOP})}=5.8 \mathrm{~Hz}, \mathrm{CH}_{3} \mathrm{CH}_{2} \mathrm{OP}\right) .{ }^{31} \mathrm{P}-\mathrm{NMR}\left(243 \mathrm{MHz}, \mathrm{CDCl}_{3}\right)$ : $\delta=21.85$. Anal. Calcd. for $\mathrm{C}_{23} \mathrm{H}_{26} \mathrm{BrN}_{4} \mathrm{O}_{7} \mathrm{P}: \mathrm{C}, 47.52 ; \mathrm{H}, 4.51 ; \mathrm{N}, 9.64$. Found: $\mathrm{C}, 47.75 ; \mathrm{H}, 4.54 ; \mathrm{N}, 9.39$.

Diethyl trans-\{5-[6-bromo-3-(2-fluorobenzyl)-4-oxo-3,4-dihydroquinazolin-2-yl]-2-methylisoxazolidin-3-yl\}phosphonate (trans-11f). Data presented below were extracted from spectra of a 88:12 mixture of trans-11f and cis-11f. Yellowish oil. IR (film, $\mathrm{cm}^{-1}$ ) $v_{\max }: 3069,2981,2929,2909,1614,1567,1490,1456,1353$, 1285, 1116, 1025, 964, 869, 760, 691. ${ }^{1} \mathrm{H}-\mathrm{NMR}\left(600 \mathrm{MHz}, \mathrm{CDCl}_{3}\right): \delta=8.31\left(\mathrm{~d},{ }^{4} J=2.1 \mathrm{~Hz}, 1 \mathrm{H}, \mathrm{HC}^{\prime}\right)$, $7.90\left(\mathrm{dd},{ }^{3} J=8.9 \mathrm{~Hz},{ }^{4} J=2.1 \mathrm{~Hz}, 1 \mathrm{H}, \mathrm{HC}^{\prime}\right), 7.84\left(\mathrm{~d},{ }^{3} J=8.9 \mathrm{~Hz}, 1 \mathrm{H}, \mathrm{HC} 8^{\prime}\right), 7.58-7.55(\mathrm{~m}, 1 \mathrm{H})$, 7.40-7.36 (m, 1H), 7.21-7.18 (m, 1H), 7.16-7.13 (m, 1H), $5.73\left(\mathrm{AB}, J_{\mathrm{AB}}=12.4 \mathrm{~Hz}, 1 \mathrm{H}, \mathrm{N}_{-} \mathrm{CH}_{2 \mathrm{~b}}\right), 5.71$ $\left(\mathrm{AB}, J_{\mathrm{AB}}=12.4 \mathrm{~Hz}, 1 \mathrm{H}, \mathrm{N}-\mathrm{CH}_{2 \mathrm{a}}\right), 5.25\left(\mathrm{dd},{ }^{3} J_{(\mathrm{H} 5-\mathrm{H} 4 \beta)}=7.9 \mathrm{~Hz},{ }^{3} J_{(\mathrm{H} 5-\mathrm{H} 4 \alpha)}=6.2 \mathrm{~Hz}, 1 \mathrm{H}, \mathrm{HC} 5\right), 4.33-4.18$ (m, 4H, $\left.2 \times \mathrm{CH}_{2} \mathrm{OP}\right), 3.42-3.39(\mathrm{~m}, 1 \mathrm{H}, \mathrm{C} 3), 3.05\left(\mathrm{~s}, 3 \mathrm{H}, \mathrm{CH}_{3}-\mathrm{N}\right), 3.03-2.96\left(\mathrm{~m}, 1 \mathrm{H}, \mathrm{H}_{\beta} \mathrm{C} 4\right), 2.96$ $\left(\mathrm{dddd},{ }^{3} J_{(\mathrm{H} 4 \alpha-\mathrm{P})}=12.5 \mathrm{~Hz},{ }^{2} J_{(\mathrm{H} 4 \alpha-\mathrm{H} 4 \beta)}=12.5 \mathrm{~Hz},{ }^{3} J_{(\mathrm{H} 4 \alpha-\mathrm{H} 3)}=8.9 \mathrm{~Hz},{ }^{3} J_{(\mathrm{H} 4 \alpha-\mathrm{H} 5)}=6.2 \mathrm{~Hz}, 1 \mathrm{H}, \mathrm{H}_{\alpha} \mathrm{C} 4\right)$, $1.42\left(\mathrm{t},{ }^{3} \mathrm{~J}=7.0 \mathrm{~Hz}, 3 \mathrm{H}, \mathrm{CH}_{3} \mathrm{CH}_{2} \mathrm{OP}\right), 1.39\left(\mathrm{t},{ }^{3} \mathrm{~J}=7.1 \mathrm{~Hz}, 3 \mathrm{H}, \mathrm{CH}_{3} \mathrm{CH}_{2} \mathrm{OP}\right) .{ }^{13} \mathrm{C}-\mathrm{NMR}\left(151 \mathrm{MHz}, \mathrm{CDCl}_{3}\right)$ : $\delta=165.94(\mathrm{C}=\mathrm{O}), 163.31,161.19\left(\mathrm{~d},{ }^{1} J_{(\mathrm{CF})}=248.8 \mathrm{~Hz}, \mathrm{C} 2{ }^{\prime \prime}\right), 149.96,137.25,130.81\left(\mathrm{~d},{ }^{3} J_{(\mathrm{CCCF})}=3.5 \mathrm{~Hz}\right.$, 
$\left.\mathrm{C}^{\prime \prime}\right), 130.52\left(\mathrm{~d},{ }^{3} J_{(\mathrm{CCCF})}=8.0 \mathrm{~Hz}, \mathrm{C} 6{ }^{\prime \prime}\right), 129.68,125.94,124.26\left(\mathrm{~d},{ }^{4} J_{(\mathrm{CCCCF})}=3.4 \mathrm{~Hz}, \mathrm{C} 5{ }^{\prime \prime}\right), 122.93(\mathrm{~d}$, $\left.{ }^{2} J_{(\mathrm{CCF})}=14.5 \mathrm{~Hz}, \mathrm{C} 3^{\prime \prime}\right), 120.75,116.65,115.66\left(\mathrm{~d},{ }^{2} J_{(\mathrm{CCF})}=21.0 \mathrm{~Hz}, \mathrm{C} 1 "\right), 80.14\left(\mathrm{dd},{ }^{3} J_{(\mathrm{CCCP})}=8.1 \mathrm{~Hz}\right.$, C5), $64.42\left(\mathrm{~d},{ }^{1} J_{(\mathrm{CP})}=168.3 \mathrm{~Hz}, \mathrm{C} 3\right), 63.25\left(\mathrm{~d},{ }^{2} \mathrm{~J}_{(\mathrm{COP})}=6.5 \mathrm{~Hz}, \mathrm{CH}_{2} \mathrm{OP}\right), 63.03\left(\mathrm{~d},{ }^{3} \mathrm{~J}=4.3 \mathrm{~Hz}, \mathrm{~N}-\mathrm{CH}_{2}\right)$, $62.43\left(\mathrm{~d},{ }^{2} J_{(\mathrm{COP})}=7.2 \mathrm{~Hz}, \mathrm{CH}_{2} \mathrm{OP}\right), 46.59\left(\mathrm{CH}_{3} \mathrm{~N}\right), 37.89(\mathrm{C} 4), 16.55\left(\mathrm{~d},{ }^{3} J_{(\mathrm{CCOP})}=5.7 \mathrm{~Hz}, \mathrm{CH}_{3} \mathrm{CH}_{2} \mathrm{OP}\right)$, $16.50\left(\mathrm{~d},{ }^{3} J_{(\mathrm{CCOP})}=5.8 \mathrm{~Hz}, \mathrm{CH}_{3} \mathrm{CH}_{2} \mathrm{OP}\right) .{ }^{31} \mathrm{P}-\mathrm{NMR}\left(243 \mathrm{MHz}, \mathrm{CDCl}_{3}\right): \delta=22.01$. Anal. Calcd. for $\mathrm{C}_{23} \mathrm{H}_{26} \mathrm{BrFN}_{3} \mathrm{O}_{5} \mathrm{P}: \mathrm{C}, 49.83 ; \mathrm{H}, 4.73 ; \mathrm{N}, 7.58$. Found: $\mathrm{C}, 49.49 ; \mathrm{H}, 4.53 ; \mathrm{N}, 7.71$ (obtained on a 88:12 mixture of trans-11f and cis-11f).

Diethyl trans-\{5-[6-bromo-3-(3-fluorobenzyl)-4-oxo-3,4-dihydroquinazolin-2-yl]-2-methylisoxazolidin-3-yl]phosphonate (trans-11g). Yellowish oil. IR (film, $\mathrm{cm}^{-1}$ ) $v_{\max }$ : 3071, 2979, 2926, 2853, 1613, 1572, 1490, 1452, 1415, $1345,1285,1255,1114,1055,1025,966,836,789,749 .{ }^{1} \mathrm{H}-\mathrm{NMR}\left(200 \mathrm{MHz}, \mathrm{CDCl}_{3}\right): \delta=8.35-8.33(\mathrm{~m}, 1 \mathrm{H})$, 7.91-7.89 (m, 1H), 7.84-7.82 (m, 1H), 7.41-7.37 (m, 1H), 7.30-7.28 (m, 1H), 7.26-7.24 (m, 1H), 7.08-7.05 $(\mathrm{m}, 1 \mathrm{H}), 5.64\left(\mathrm{~s}, 1 \mathrm{H}, \mathrm{N}-\mathrm{CH}_{2}\right), 5.24\left(\mathrm{dd},{ }^{3} J_{(\mathrm{H} 5-\mathrm{H} 4 \beta)}=7.9 \mathrm{~Hz},{ }^{3} J_{(\mathrm{H} 5-\mathrm{H} 4 \alpha)}=6.5 \mathrm{~Hz}, 1 \mathrm{H}, \mathrm{HC} 5\right), 4.33-4.17(\mathrm{~m}$, $\left.4 \mathrm{H}, 2 \times \mathrm{CH}_{2} \mathrm{OP}\right), 3.39-3.36(\mathrm{~m}, 1 \mathrm{H}, \mathrm{C} 3), 3.04\left(\mathrm{~s}, 3 \mathrm{H}, \mathrm{CH}_{3}-\mathrm{N}\right), 3.05-2.99\left(\mathrm{~m}, 1 \mathrm{H}, \mathrm{H}_{\beta} \mathrm{C} 4\right), 2.95$ (dddd, $\left.{ }^{3} J_{(\mathrm{H} 4 \alpha-\mathrm{P})}=12.7 \mathrm{~Hz},{ }^{2} J_{(\mathrm{H} 4 \alpha-\mathrm{H} 4 \beta)}=12.7 \mathrm{~Hz},{ }^{3} J_{(\mathrm{H} 4 \alpha-\mathrm{H} 3)}=9.7 \mathrm{~Hz},{ }^{3} J_{(\mathrm{H} 4 \alpha-\mathrm{H} 5)}=6.5 \mathrm{~Hz}, 1 \mathrm{H}, H_{\alpha} \mathrm{C} 4\right), 1.41$ $\left(\mathrm{t},{ }^{3} \mathrm{~J}=7.0 \mathrm{~Hz}, 3 \mathrm{H}, \mathrm{CH}_{3} \mathrm{CH}_{2} \mathrm{OP}\right), 1.39\left(\mathrm{t},{ }^{3} \mathrm{~J}=6.9 \mathrm{~Hz}, 3 \mathrm{H}, \mathrm{CH}_{3} \mathrm{CH}_{2} \mathrm{OP}\right) .{ }^{13} \mathrm{C}-\mathrm{NMR}\left(151 \mathrm{MHz}, \mathrm{CDCl}_{3}\right)$ : $\delta=165.84(\mathrm{C}=\mathrm{O}), 163.22,162.91,\left(\mathrm{~d},{ }^{1} J_{(\mathrm{CF})}=246.7 \mathrm{~Hz}, \mathrm{C}^{\prime}\right), 149.97,138.18\left(\mathrm{~d},{ }^{3} J_{(\mathrm{CCCF})}=7.6 \mathrm{~Hz}, \mathrm{C}^{\prime}\right)$, $137.31,130.26\left(\mathrm{~d}, J=7.9 \mathrm{~Hz}, \mathrm{Cl}^{\prime}\right), 129.72,125.84,123.80\left(\mathrm{~d}^{4}{ }^{4} J_{(\mathrm{CCCCF})}=2.4 \mathrm{~Hz}, \mathrm{C} 6^{\prime}\right), 120.83,116.59,115.45$ $\left(\mathrm{d},{ }^{2} J_{(\mathrm{CCF})}=21.0 \mathrm{~Hz}, \mathrm{C} 4^{\prime}\right), 115.21\left(\mathrm{~d},{ }^{2} J_{(\mathrm{CCF})}=22.0 \mathrm{~Hz}, \mathrm{C} 2^{\prime}\right), 80.06\left(\mathrm{dd},{ }^{3} J_{(\mathrm{CCCP})}=8.0 \mathrm{~Hz}, \mathrm{C} 5\right), 68.19$ $\left(\mathrm{d},{ }^{3} \mathrm{~J}=1.7 \mathrm{~Hz}, \mathrm{~N}-\mathrm{CH}_{2}\right), 64.42\left(\mathrm{~d},{ }^{1} J_{(\mathrm{CP})}=168.3 \mathrm{~Hz}, \mathrm{C} 3\right), 63.24\left(\mathrm{~d},{ }^{2} J_{(\mathrm{COP})}=6.4 \mathrm{~Hz}, \mathrm{CH}_{2} \mathrm{OP}\right), 62.44(\mathrm{~d}$, $\left.{ }^{2} J_{(\mathrm{COP})}=7.3 \mathrm{~Hz}, \mathrm{CH}_{2} \mathrm{OP}\right), 46.57\left(\mathrm{~d},{ }^{3} J_{(\mathrm{CNCP})}=3.7 \mathrm{~Hz}, \mathrm{CH}_{3} \mathrm{~N}\right), 37.84(\mathrm{~s}, \mathrm{C} 4), 16.55\left(\mathrm{~d},{ }^{3} J_{(\mathrm{CCOP})}=5.6 \mathrm{~Hz}\right.$, $\left.\mathrm{CH}_{3} \mathrm{CH}_{2} \mathrm{OP}\right), 16.49\left(\mathrm{~d},{ }^{3} J_{(\mathrm{CCOP})}=5.9 \mathrm{~Hz}, \mathrm{CH}_{3} \mathrm{CH}_{2} \mathrm{OP}\right) .{ }^{31} \mathrm{P}-\mathrm{NMR}\left(121.5 \mathrm{MHz}, \mathrm{CDCl}_{3}\right): \delta=21.97$. Anal. Cald. for $\mathrm{C}_{23} \mathrm{H}_{26} \mathrm{BrFN}_{3} \mathrm{O}_{5} \mathrm{P}: \mathrm{C}, 49.83 ; \mathrm{H}, 4.73 ; \mathrm{N}$, 7.58. Found: $\mathrm{C}, 49.49 ; \mathrm{H}, 4.53 ; \mathrm{N}, 7.71$.

Diethyl trans\{5-[6-bromo-3-(4-fluorobenzyl)-4-oxo-3,4-dihydroquinazolin-2-yl]-2-methylisoxazolidin-3-yl\}phosphonate (trans-11h). A yellowish oil. IR (film, $\mathrm{cm}^{-1}$ ) $\gamma_{\max }$ : 3072, 2981, 2926, 2853, 1611, 1568, 1512, 1490, $1430,1351,1285,1227,1160,1114,1099,1056,1026,965,835 .{ }^{1} \mathrm{H}-\mathrm{NMR}\left(600 \mathrm{MHz}, \mathrm{CDCl}_{3}\right): \delta=8.31$ $\left(\mathrm{d},{ }^{4} J=2.2 \mathrm{~Hz}, 1 \mathrm{H}, H C 5^{\prime}\right), 7.91\left(\mathrm{dd},{ }^{3} J=8.9 \mathrm{~Hz},{ }^{4} J=2.2 \mathrm{~Hz}, 1 \mathrm{H}, H C 7^{\prime}\right), 7.84\left(\mathrm{~d},{ }^{3} J=8.9 \mathrm{~Hz}, 1 \mathrm{H}\right.$, $\left.H C 8^{\prime}\right), 7.55-7.53(\mathrm{~m}, 2 \mathrm{H}), 7.14-7.11(\mathrm{~m}, 2 \mathrm{H}), 5.63\left(\mathrm{~s}, 1 \mathrm{H}, \mathrm{N}-\mathrm{CH}_{2}\right), 5.26\left(\mathrm{dd},{ }^{3} J_{(\mathrm{H} 5-\mathrm{H} 4 \beta)}=6.4 \mathrm{~Hz}\right.$, $\left.{ }^{3} J_{(\mathrm{H} 5-\mathrm{H} 4 \alpha)}=6.4 \mathrm{~Hz}, 1 \mathrm{H}, \mathrm{HC} 5\right), 4.34-4.22\left(\mathrm{~m}, 4 \mathrm{H}, 2 \times \mathrm{CH}_{2} \mathrm{OP}\right), 3.41-3.39(\mathrm{~m}, 1 \mathrm{H}, \mathrm{C} 3), 3.07-3.00(\mathrm{~m}, 1 \mathrm{H}$, $\left.H_{\beta} \mathrm{C} 4\right), 3.06\left(\mathrm{~s}, 3 \mathrm{H}, \mathrm{CH}_{3}-\mathrm{N}\right), 2.98\left(\mathrm{dddd},{ }^{3} J_{(\mathrm{H} 4 \alpha-\mathrm{P})}=13.4 \mathrm{~Hz},{ }^{2} J_{(\mathrm{H} 4 \alpha-\mathrm{H} 4 \beta)}=13.4 \mathrm{~Hz},{ }^{3} J_{(\mathrm{H} 4 \alpha-\mathrm{H} 3)}=10.4 \mathrm{~Hz}\right.$, $\left.{ }^{3} J_{(\mathrm{H} 4 \alpha-\mathrm{H} 5)}=6.4 \mathrm{~Hz}, 1 \mathrm{H}, \mathrm{H}_{\alpha} \mathrm{C} 4\right), 1.42\left(\mathrm{t},{ }^{3} \mathrm{~J}=7.0 \mathrm{~Hz}, 3 \mathrm{H}, \mathrm{CH}_{3} \mathrm{CH}_{2} \mathrm{OP}\right), 1.40\left(\mathrm{t},{ }^{3} \mathrm{~J}=7.1 \mathrm{~Hz}, 3 \mathrm{H}\right.$, $\left.\mathrm{CH}_{3} \mathrm{CH}_{2} \mathrm{OP}\right) .{ }^{13} \mathrm{C}-\mathrm{NMR}\left(151 \mathrm{MHz}, \mathrm{CDCl}_{3}\right): \delta=165.94(\mathrm{C}=\mathrm{O}), 163.26,162.84\left(\mathrm{~d},{ }^{1} J_{(\mathrm{CF})}=247.6 \mathrm{~Hz}\right.$, $\left.\mathrm{C}^{\prime \prime}\right), 149.94,137.25,131.52\left(\mathrm{~d},{ }^{4} J_{(\mathrm{CCCCF})}=3.1 \mathrm{~Hz}, \mathrm{C} 1^{\prime \prime}\right), 130.49\left(\mathrm{~d},{ }^{3} J_{(\mathrm{CCCF})}=8.0 \mathrm{~Hz}, \mathrm{C} 2 ", \mathrm{C}{ }^{\prime \prime}\right), 129.69$, $125.89,120.75,116.65,115.62\left(\mathrm{~d},{ }^{2} J_{(\mathrm{CCF})}=21.9 \mathrm{~Hz}, \mathrm{C} 3 ", \mathrm{C}^{\prime \prime}\right), 80.09\left(\mathrm{~d},{ }^{3} J_{(\mathrm{CCP})}=8.1 \mathrm{~Hz}, \mathrm{C} 5\right), 68.40$ $\left(\mathrm{N}-\mathrm{CH}_{2}\right), 64.43\left(\mathrm{~d},{ }^{1} J_{(\mathrm{CP})}=168.3 \mathrm{~Hz}, \mathrm{C} 3\right), 63.26\left(\mathrm{~d},{ }^{2} J_{(\mathrm{COP})}=6.5 \mathrm{~Hz}, \mathrm{CH}_{2} \mathrm{OP}\right), 62.45\left(\mathrm{~d},{ }^{2} J_{(\mathrm{COP})}=6.8 \mathrm{~Hz}\right.$, $\left.\mathrm{CH}_{2} \mathrm{OP}\right), 46.59\left(\mathrm{CH}_{3} \mathrm{~N}\right), 37.87(\mathrm{C} 4), 16.56\left(\mathrm{~d},{ }^{3} J_{(\mathrm{CCOP})}=5.8 \mathrm{~Hz}, \mathrm{CH}_{3} \mathrm{CH}_{2} \mathrm{OP}\right), 16.46\left(\mathrm{~d},{ }^{3} J_{(\mathrm{CCOP})}=5.3 \mathrm{~Hz}\right.$, $\left.\mathrm{CH}_{3} \mathrm{CH}_{2} \mathrm{OP}\right) .{ }^{31} \mathrm{P}-\mathrm{NMR}\left(243 \mathrm{MHz}, \mathrm{CDCl}_{3}\right): \delta=22.00$. Anal. Calcd. for $\mathrm{C}_{23} \mathrm{H}_{26} \mathrm{BrFN}_{3} \mathrm{O} 5 \mathrm{P}: \mathrm{C}, 49.83 ; \mathrm{H}$, $4.73 ; \mathrm{N}, 7.58$. Found: $\mathrm{C}, 50.20 ; \mathrm{H}, 4.62 ; \mathrm{N}, 7.32$.

Diethyl trans-\{5-[6-bromo-3-(2,4-difluorobenzyl)-4-oxo-3,4-dihydroquinazolin-2-yl]-2-methylisoxazolidin-3-yl\} phosphonate (trans-11i). Data presented below were extracted from spectra of a 92:8 mixture of trans-11i and cis-11i. Yellowish oil. IR (film, $\mathrm{cm}^{-1}$ ) $\nu_{\max }$ : 3079, 2959, 2924, 2853, 1738, 1689, 1613, 1565, 1509, 1490, 1416, 1351, 1280, 1141, 1100, 961, 836, 798. ${ }^{1} \mathrm{H}-\mathrm{NMR}\left(600 \mathrm{MHz}, \mathrm{CDCl}_{3}\right): \delta=8.30\left(\mathrm{~d},{ }^{4} J=2.1 \mathrm{~Hz}\right.$, $\left.1 \mathrm{H}, \mathrm{HC}^{\prime}\right), 7.92\left(\mathrm{dd},{ }^{3} \mathrm{~J}=8.8 \mathrm{~Hz},{ }^{4} \mathrm{~J}=2.1 \mathrm{~Hz}, 1 \mathrm{H}, \mathrm{HCZ}^{\prime}\right), 7.85\left(\mathrm{~d},{ }^{3} J=8.8 \mathrm{~Hz}, 1 \mathrm{H}, \mathrm{HC} 8^{\prime}\right), 7.59-7.55$ $(\mathrm{m}, 1 \mathrm{H}), 6.95-6.89(\mathrm{~m}, 2 \mathrm{H}), 5.68\left(\mathrm{AB}, J_{\mathrm{AB}}=13.3 \mathrm{~Hz}, 1 \mathrm{H}, \mathrm{N}-\mathrm{CH}_{2 \mathrm{~b}}\right), 5.66\left(\mathrm{AB}, J_{\mathrm{AB}}=13.3 \mathrm{~Hz}, 1 \mathrm{H}\right.$, $\left.\mathrm{N}-\mathrm{CH}_{2 \mathrm{a}}\right), 5.25\left(\mathrm{dd},{ }^{3} J_{(\mathrm{H} 5-\mathrm{H} 4 \beta)}=7.7 \mathrm{~Hz},{ }^{3} J_{(\mathrm{H} 5-\mathrm{H} 4 \alpha)}=6.5 \mathrm{~Hz}, 1 \mathrm{H}, \mathrm{HC} 5\right), 4.33-4.18\left(\mathrm{~m}, 4 \mathrm{H}, 2 \times \mathrm{CH}_{2} \mathrm{OP}\right)$, 3.41-3.38 (m, 1H, HC3), 3.07-3.01 (m, 1H, $\left.\mathrm{H}_{\beta} \mathrm{C} 4\right), 3.05\left(\mathrm{~s}, 3 \mathrm{H}, \mathrm{CH}_{3}-\mathrm{N}\right), 2.98$ (dddd, ${ }^{3} J_{(\mathrm{H} 4 \alpha-\mathrm{P})}=12.8 \mathrm{~Hz}$, $\left.{ }^{2} J_{(\mathrm{H} 4 \alpha-\mathrm{H} 4 \beta)}=12.8 \mathrm{~Hz},{ }^{3} J_{(\mathrm{H} 4 \alpha-\mathrm{H} 3)}=9.7 \mathrm{~Hz},{ }^{3} J_{(\mathrm{H} 4 \alpha-\mathrm{H} 5)}=6.5 \mathrm{~Hz}, 1 \mathrm{H}, \mathrm{H}_{\alpha} \mathrm{C} 4\right), 1.41\left(\mathrm{t},{ }^{3} \mathrm{~J}=7.0 \mathrm{~Hz}\right.$, $\left.3 \mathrm{H}, \mathrm{CH}_{3} \mathrm{CH}_{2} \mathrm{OP}\right), 1.40\left(\mathrm{t},{ }^{3} \mathrm{~J}=7.0 \mathrm{~Hz}, 3 \mathrm{H}, \mathrm{CH}_{3} \mathrm{CH}_{2} \mathrm{OP}\right) .{ }^{13} \mathrm{C}-\mathrm{NMR}\left(151 \mathrm{MHz}, \mathrm{CDCl}_{3}\right): \delta=165.82$ $(\mathrm{C}=\mathrm{O}), 163.32\left(\mathrm{dd},{ }^{1} J_{(\mathrm{CF})}=250.9 \mathrm{~Hz},{ }^{3} J_{(\mathrm{CCCF})}=12.1 \mathrm{~Hz}, \mathrm{C} 2{ }^{\prime \prime}\right), 163.20,161.50\left(\mathrm{dd},{ }^{1} J_{(\mathrm{CF})}=251.4 \mathrm{~Hz}\right.$, $\left.{ }^{3} J_{(\mathrm{CCCF})}=12.2 \mathrm{~Hz}, \mathrm{C} 4 "\right), 149.87,137.31,132.09\left(\mathrm{dd},{ }^{3} J_{(\mathrm{CCCF})}=9.8 \mathrm{~Hz},{ }^{3} J_{(\mathrm{CCCF})}=4.9 \mathrm{~Hz}, \mathrm{C6}{ }^{\prime \prime}\right), 129.71$, 
$125.87,120.81,118.98\left(\mathrm{dd},{ }^{2} J_{(\mathrm{CCF})}=14.4 \mathrm{~Hz},{ }^{4} J_{(\mathrm{CCCCF})}=3.4 \mathrm{~Hz}, \mathrm{C1}^{\prime \prime}\right), 116.58,111.51\left(\mathrm{dd},{ }^{2} J_{(\mathrm{CCF})}=21.1 \mathrm{~Hz}\right.$, $\left.{ }^{4} J_{(\mathrm{CCCCF})}=3.5 \mathrm{~Hz}, \mathrm{C} 5 "\right), 104.21\left(\mathrm{dd},{ }^{2} J_{(\mathrm{CCF})}=25.3 \mathrm{~Hz},{ }^{2} J_{(\mathrm{CCF})}=25.4 \mathrm{~Hz}, \mathrm{C} 3 "\right), 80.09\left(\mathrm{dd},{ }^{3} J_{(\mathrm{CCCP})}=7.9 \mathrm{~Hz}\right.$, C5), $64.43\left(\mathrm{~d},{ }^{1} J_{(\mathrm{CP})}=168.3 \mathrm{~Hz}, \mathrm{C} 3\right), 63.26\left(\mathrm{~d},{ }^{2} J_{(\mathrm{COP})}=6.5 \mathrm{~Hz}, \mathrm{CH}_{2} \mathrm{OP}\right), 62.47\left(\mathrm{~d},{ }^{3} J_{(\mathrm{CCCF})}=2.7 \mathrm{~Hz}\right.$, $\left.\mathrm{N}-\mathrm{CH}_{2}\right), 62.43\left(\mathrm{~d},{ }^{2} \mathrm{~J}_{(\mathrm{COP})}=6.3 \mathrm{~Hz}, \mathrm{CH}_{2} \mathrm{OP}\right), 46.57\left(\mathrm{~d},{ }^{3} J_{(\mathrm{CNCP})}=4.0 \mathrm{~Hz}, \mathrm{CH}_{3} \mathrm{~N}\right), 37.89(\mathrm{C} 4), 16.56(\mathrm{~d}$, $\left.{ }^{3} J_{(\mathrm{CCOP})}=5.7 \mathrm{~Hz}, \mathrm{CH}_{3} \mathrm{CH}_{2} \mathrm{OP}\right), 16.50\left(\mathrm{~d},{ }^{3} J_{(\mathrm{CCOP})}=5.6 \mathrm{~Hz}, \mathrm{CH}_{3} \mathrm{CH}_{2} \mathrm{OP}\right) .{ }^{31} \mathrm{P}-\mathrm{NMR}\left(243 \mathrm{MHz}, \mathrm{CDCl}_{3}\right):$ $\delta=21.98$. Anal. Calcd. for $\mathrm{C}_{23} \mathrm{H}_{25} \mathrm{BrF}_{2} \mathrm{~N}_{3} \mathrm{O}_{5} \mathrm{P} \times 0.75 \mathrm{H}_{2} \mathrm{O}: \mathrm{C}, 47.15 ; \mathrm{H}, 4.56 ; \mathrm{N}, 7.17$. Found: $\mathrm{C}, 46.84$; $\mathrm{H}, 4.18 ; \mathrm{N}, 6.96$ (obtained on a 92:8 mixture of trans-11i and cis-11i).

Diethyl trans-\{5-[6-bromo-3-methyl-4-oxo-3,4-dihydroquinazolin-2-yl]-2-methylisoxazolidin-3-yl\}phosphonate (trans-11j). A yellowish oil. IR (film, $\mathrm{cm}^{-1}$ ) $v_{\max }$ : 3521, 3477, 2976, 2912, 2855, 1687, 1606, 1470, 1308, 1265, 1050, 1023, 972, 849, 574. ${ }^{1} \mathrm{H}-\mathrm{NMR}\left(600 \mathrm{MHz}, \mathrm{CDCl}_{3}\right): \delta=8.42\left(\mathrm{~d},{ }^{4} J=2.3 \mathrm{~Hz}, 1 \mathrm{H}\right.$, $\left.H C 5^{\prime}\right), 7.82\left(\mathrm{dd},{ }^{3} \mathrm{~J}=8.7 \mathrm{~Hz},{ }^{4} \mathrm{~J}=2.3 \mathrm{~Hz}, 1 \mathrm{H}, H C 7^{\prime}\right), 7.56\left(\mathrm{~d},{ }^{3} \mathrm{~J}=8.7 \mathrm{~Hz}, 1 \mathrm{H}, H C 8^{\prime}\right), 5.18(\mathrm{dd}$, $\left.{ }^{3} J_{(\mathrm{H} 5-\mathrm{H} 4 \beta)}=7.6 \mathrm{~Hz},{ }^{3} J_{(\mathrm{H} 5-\mathrm{H} 4 \alpha)}=5.7 \mathrm{~Hz}, 1 \mathrm{H}, \mathrm{HC} 5\right), 4.29-4.23\left(\mathrm{~m}, 4 \mathrm{H}, 2 \times \mathrm{CH}_{2} \mathrm{OP}\right), 3.75\left(\mathrm{~s}, 3 \mathrm{H}, \mathrm{CH}_{3}\right), 3.71$ $\left(\mathrm{dddd},{ }^{3} J_{(\mathrm{H} 4 \alpha-\mathrm{P})}=12.6 \mathrm{~Hz},{ }^{2} J_{(\mathrm{H} 4 \alpha-\mathrm{H} 4 \beta)}=11.3 \mathrm{~Hz},{ }^{3} J_{(\mathrm{H} 4 \alpha-\mathrm{H} 3)}=9.1 \mathrm{~Hz},{ }^{3} J_{(\mathrm{H} 4 \alpha-\mathrm{H} 5)}=5.7 \mathrm{~Hz}, 1 \mathrm{H}, H_{\alpha} \mathrm{C} 4\right)$, $3.35\left(\mathrm{ddd},{ }^{3} J_{(\mathrm{H} 3-\mathrm{H} 4 \alpha)}=9.1 \mathrm{~Hz},{ }^{3} J_{(\mathrm{H} 3-\mathrm{H} 4 \beta)}=7.6 \mathrm{~Hz},{ }^{2} J_{(\mathrm{H} 3-\mathrm{P})}=2.8 \mathrm{~Hz}, 1 \mathrm{H}, \mathrm{HC} 3\right), 2.87\left(\mathrm{~s}, 3 \mathrm{H}, \mathrm{CH}_{3} \mathrm{~N}\right), 2.80$ $\left(\mathrm{dddd},{ }^{3} J_{(\mathrm{H} 4 \beta-\mathrm{P})}=15.3 \mathrm{~Hz},{ }^{2} J_{(\mathrm{H} 4 \beta-\mathrm{H} 4 \alpha)}=11.3 \mathrm{~Hz},{ }^{3} J_{(\mathrm{H} 4 \beta-\mathrm{H} 3)}=7.6 \mathrm{~Hz},{ }^{3} J_{(\mathrm{H} 4 \beta-\mathrm{H} 5)}=7.6 \mathrm{~Hz}, 1 \mathrm{H}, H_{\beta} \mathrm{C} 4\right)$, $1.41\left(\mathrm{t},{ }^{3} \mathrm{~J}=7.0 \mathrm{~Hz}, 3 \mathrm{H}, \mathrm{CH}_{3} \mathrm{CH}_{2} \mathrm{OP}\right), 1.40\left(\mathrm{t},{ }^{3} \mathrm{~J}=7.1 \mathrm{~Hz}, 3 \mathrm{H}, \mathrm{CH}_{3} \mathrm{CH}_{2} \mathrm{OP}\right) .{ }^{13} \mathrm{C}-\mathrm{NMR}\left(151 \mathrm{MHz}, \mathrm{CDCl}_{3}\right)$ : $\delta=161.31(\mathrm{C}=\mathrm{O}), 152.70,145.34,137.33,129.44,129.37,122.31,121.02,76.29\left(\mathrm{~d},{ }^{3} J_{(\mathrm{CCCP})}=7.8 \mathrm{~Hz}, \mathrm{C} 5\right)$, $64.35\left(\mathrm{~d},{ }^{1} J_{(\mathrm{CP})}=170.1 \mathrm{~Hz}, \mathrm{C} 3\right), 62.89\left(\mathrm{~d},{ }^{2} J_{(\mathrm{COP})}=6.6 \mathrm{~Hz}, \mathrm{CH}_{2} \mathrm{OP}\right), 62.73\left(\mathrm{~d},{ }^{2} J_{(\mathrm{COP})}=7.2 \mathrm{~Hz}, \mathrm{CH}_{2} \mathrm{OP}\right)$, $47.15\left(\mathrm{~d},{ }^{3} J_{(\mathrm{CNCP})}=6.4 \mathrm{~Hz} \mathrm{CH}{ }_{3} \mathrm{~N}\right), 34.38(\mathrm{C} 4), 30.97\left(\mathrm{CH}_{3}\right), 16.56\left(\mathrm{~d},{ }^{3} J_{(\mathrm{CCOP})}=4.9 \mathrm{~Hz}, \mathrm{CH}_{3} \mathrm{CH}_{2} \mathrm{OP}\right)$, $16.53\left(\mathrm{~d},{ }^{3} J_{(\mathrm{CCOP})}=5.1 \mathrm{~Hz}, \mathrm{CH}_{3} \mathrm{CH}_{2} \mathrm{OP}\right) .{ }^{31} \mathrm{P}-\mathrm{NMR}\left(243 \mathrm{MHz}, \mathrm{CDCl}_{3}\right): \delta=21.93$. Anal. Calcd. for $\mathrm{C}_{17} \mathrm{H}_{23} \mathrm{BrN}_{3} \mathrm{O}_{5} \mathrm{P}: \mathrm{C}, 44.36 ; \mathrm{H}, 5.04 ; \mathrm{N}, 9.13$. Found: $\mathrm{C}, 44.15 ; \mathrm{H}, 4.75 ; \mathrm{N}, 9.03$.

Diethyl trans-\{5-[6-bromo-3-ethyl-4-oxo-3,4-dihydroquinazolin-2-yl]-2-methylisoxazolidin-3-yl\}phosphonate (trans-11k). Colorless oil. IR (film, cm ${ }^{-1}$ ) $v_{\max }$ : 3055, 2981, 2929, 2854, 1687, 1613, 1569, 1493, 1430, $1383,1285,1241,1117,1056,1024,967,836 .{ }^{1} \mathrm{H}-\mathrm{NMR}\left(600 \mathrm{MHz}, \mathrm{CDCl}_{3}\right): \delta=8.32\left(\mathrm{~d},{ }^{4} J=2.2 \mathrm{~Hz}\right.$, $\left.1 \mathrm{H}, H C 5^{\prime}\right), 7.90\left(\mathrm{dd},{ }^{3} J=8.8 \mathrm{~Hz},{ }^{4} \mathrm{~J}=2.2 . \mathrm{Hz}, 1 \mathrm{H}, H C 7^{\prime}\right), 7.82\left(\mathrm{~d},{ }^{3} \mathrm{~J}=8.8 \mathrm{~Hz}, 1 \mathrm{H}, H C 8^{\prime}\right), 5.23(\mathrm{dd}$, $\left.{ }^{3} J_{(\mathrm{H} 5-\mathrm{H} 4 \beta)}=8.0 \mathrm{~Hz},{ }^{3} J_{(\mathrm{H} 5-\mathrm{H} 4 \alpha)}=6.0 \mathrm{~Hz}, 1 \mathrm{H}, \mathrm{HC} 5\right), 4.68\left(\mathrm{q},{ }^{3} \mathrm{~J}=7.2 \mathrm{~Hz}, 2 \mathrm{H}, \mathrm{CH}_{3} \mathrm{CH}_{2}\right), 4.33-4.21(\mathrm{~m}$, $\left.4 \mathrm{H}, 2 \times \mathrm{CH}_{2} \mathrm{OP}\right), 3.45-3.43(\mathrm{~m}, 1 \mathrm{H}, \mathrm{HC} 3), 3.07\left(\mathrm{~s}, 3 \mathrm{H}, \mathrm{CH}_{3} \mathrm{~N}\right), 3.06-3.01\left(\mathrm{~m}, 1 \mathrm{H}, \mathrm{H}_{\beta} \mathrm{C} 4\right), 2.97$ (dddd, $\left.{ }^{3} J_{(\mathrm{H} 4 \alpha-\mathrm{P})}=12.6 \mathrm{~Hz},{ }^{2} J_{(\mathrm{H} 4 \alpha-\mathrm{H} 4 \beta)}=12.6 \mathrm{~Hz},{ }^{3} J_{(\mathrm{H} 4 \alpha-\mathrm{H} 3)}=9.4 \mathrm{~Hz},{ }^{3} J_{(\mathrm{H} 4 \alpha-\mathrm{H} 5)}=6.0 \mathrm{~Hz}, 1 \mathrm{H}, H_{\alpha} \mathrm{C} 4\right), 1.55(\mathrm{t}$, $\left.{ }^{3} \mathrm{~J}=7.2 \mathrm{~Hz}, 3 \mathrm{H}, \mathrm{CH}_{3} \mathrm{CH}_{2}\right), 1.42\left(\mathrm{t},{ }^{3} \mathrm{~J}=7.0 \mathrm{~Hz}, 3 \mathrm{H}, \mathrm{CH}_{3} \mathrm{CH}_{2} \mathrm{OP}\right), 1.39\left(\mathrm{t},{ }^{3} \mathrm{~J}=6.8 \mathrm{~Hz}, 3 \mathrm{H}, \mathrm{CH}_{3} \mathrm{CH}_{2} \mathrm{OP}\right)$. ${ }^{13} \mathrm{C}-\mathrm{NMR}\left(151 \mathrm{MHz}, \mathrm{CDCl}_{3}\right): \delta=166.33(\mathrm{C}=\mathrm{O}), 163.63,149.78,137.01,129.63,126.03,120.47,116.78$, $80.22\left(\mathrm{~d},{ }^{3} J_{(\mathrm{CCCP})}=7.9 \mathrm{~Hz}, \mathrm{C} 5\right), 64.38\left(\mathrm{~d},{ }^{1} J_{(\mathrm{CP})}=168.0 \mathrm{~Hz}, \mathrm{C} 3\right), 63.28\left(\mathrm{~d},{ }^{2} J_{(\mathrm{COP})}=6.4 \mathrm{~Hz}, \mathrm{CH}_{2} \mathrm{OP}\right), 62.41$ $\left(\mathrm{d},{ }^{2} J_{(\mathrm{COP})}=6.7 \mathrm{~Hz}, \mathrm{CH}_{2} \mathrm{OP}\right), 47.21\left(\mathrm{CH}_{3} \mathrm{~N}\right), 38.01(\mathrm{C} 4), 29.69\left(\mathrm{CH}_{3} \mathrm{CH}_{2}\right) 16.56\left(\mathrm{~d},{ }^{3} J_{(\mathrm{CCOP})}=5.5 \mathrm{~Hz}\right.$, $\left.\mathrm{CH}_{3} \mathrm{CH}_{2} \mathrm{OP}\right), 16.50\left(\mathrm{~d},{ }^{3} J_{(\mathrm{CCOP})}=6.2 \mathrm{~Hz}, \mathrm{CH}_{3} \mathrm{CH}_{2} \mathrm{OP}\right), 14.29\left(\mathrm{CH}_{3} \mathrm{CH}_{2}\right) .{ }^{31} \mathrm{P}-\mathrm{NMR}\left(243 \mathrm{MHz}, \mathrm{CDCl}_{3}\right)$ : $\delta=22.08$. Anal. Calcd. for $\mathrm{C}_{18} \mathrm{H}_{25} \mathrm{BrN}_{3} \mathrm{O}_{5} \mathrm{P}: \mathrm{C}, 45.58 ; \mathrm{H}, 5.31 ; \mathrm{N}, 8.86$. Found: $\mathrm{C}, 45.37 ; \mathrm{H}, 5.31 ; \mathrm{N}, 8.54$.

\subsection{Antiviral Activity Assays}

The compounds were evaluated against different herpesviruses, including herpes simplex virus type 1 (HSV-1) strain KOS, thymidine kinase-deficient (TK-) HSV-1 KOS strain resistant to ACV $\left(\mathrm{ACV}^{\mathrm{r}}\right)$, herpes simplex virus type 2 (HSV-2) strain G, varicella-zoster virus (VZV) strain Oka, $\mathrm{TK}^{-}$VZV strain 07-1, human cytomegalovirus (HCMV) strains AD-169 and Davis, as well as vaccinia virus, adeno virus-2, vesicular stomatitis virus, para-influenza-3 virus, reovirus-1, Sindbis virus, Coxsackie virus B4, Punta Toro virus, respiratory syncytial virus (RSV), feline coronovirus (FIPV), and influenza A virus subtypes H1N1 (A/PR/8), H3N2 (A/HK/7/87) and influenza B virus (B/HK/5/72). The antiviral assays were based on the inhibition of virus-induced cytopathicity or plaque formation in human embryonic lung (HEL) fibroblasts, African green monkey kidney cells (Vero), human epithelial cervix carcinoma cells (HeLa), Crandell-Rees feline kidney cells (CRFK), or Madin Darby canine kidney cells (MDCK). Confluent cell cultures in microtiter 96-well plates were inoculated with 100 CCID $_{50}$ of virus ( $1 \mathrm{CCID}_{50}$ being the virus dose to infect $50 \%$ of the cell cultures) or with 20 plaque forming units (PFU) and the cell cultures were incubated in the presence of varying concentrations of the test compounds. 
Viral cytopathicity or plaque formation (VZV) was recorded as soon as it reached completion in the control virus-infected cell cultures that were not treated with the test compounds. Antiviral activity was expressed as the $\mathrm{EC}_{50}$ or compound concentration required to reduce virus-induced cytopathicity or viral plaque formation by $50 \%$. Cytotoxicity of the test compounds was expressed as the minimum cytotoxic concentration (MCC) or the compound concentration that caused a microscopically detectable alteration of cell morphology. Alternatively, the cytostatic activity of the test compounds was measured based on inhibition of cell growth. HEL cells were seeded at a rate of $5 \times 10^{3}$ cells/well into 96-well microtiter plates and allowed to proliferate for $24 \mathrm{~h}$. Then, medium containing different concentrations of the test compounds was added. After three days of incubation at $37^{\circ} \mathrm{C}$, the cell number was determined with a Coulter counter. The cytostatic concentration was calculated as the $\mathrm{CC}_{50}$, or the compound concentration required to reduce cell proliferation by $50 \%$ relative to the number of cells in the untreated controls.

\subsection{Cytostatic Activity against Immortalized Cell Lines}

Murine leukemia (L1210), human T-lymphocyte (CEM), human cervix carcinoma (HeLa), and immortalized human dermal microvascular endothelial cells (HMEC-1) were suspended at $300,000-500,000$ cells $/ \mathrm{mL}$ of culture medium, and $100 \mu \mathrm{L}$ of a cell suspension was added to $100 \mu \mathrm{L}$ of an appropriate dilution of the test compounds in $200 \mu \mathrm{L}$-wells of 96 -well microtiter plates. After incubation at $37^{\circ} \mathrm{C}$ for two (L1210), three (CEM), or four (HeLa) days, the cell number was determined using a Coulter counter. The $\mathrm{IC}_{50}$ was defined as the compound concentration required to inhibit cell proliferation by $50 \%$.

\section{Conclusions}

A series of isoxazolidine-conjugates of quinazolinones trans-11a-k and cis-11a-k were obtained from $\mathrm{N}$-methyl $\mathrm{C}$-(diethoxyphosphoryl)nitrone and selected N3-substituted 6-bromo-2-vinylquinazolinones. The trans-isoxazolidine cycloadducts (trans-11a, trans-11b, trans-11c, trans-11d, trans-11e, trans-11g, trans-11h, trans-11j, trans-11k) and isoxazolidine cis-11a, or the respective mixtures of isoxazolidines (trans-11f/cis-11f (95:5) and trans-11i/cis-11i (92:8)) were evaluated for their antiviral activity toward variety of DNA and RNA viruses. Almost all compounds were active against VZV and among them trans-11b, trans-11d, trans-11g, and trans-11h were the most potent $\left(\mathrm{EC}_{50}=5.8-11.6 \mu \mathrm{M}\right)$ and, at the same time, exhibited lower cytotoxicity toward uninfected cell lines $\left(C_{50}=33-42 \mu \mathrm{M}\right)$. Furthermore, (isoxazolidine)phosphonates trans-11d, trans-11g, trans-11h, and trans-11i/cis-11i (92:8) showed the highest activity against $\mathrm{HCMV}\left(\mathrm{EC}_{50}=8.9-12.5 \mu \mathrm{M}\right)$. On the other hand, several compounds exhibited moderate cytostatic effect toward the CEM cell line $\left(\mathrm{IC}_{50}=9.6-17 \mu \mathrm{M}\right)$, however, slightly higher than that of 5-fluorouracil used as the reference drug.

It was proved that installation of functionalized benzyl groups at N3 in the quinazolinone moiety is essential for inhibitory properties toward both VZV and HCMV. At the same time, it was noticed that incorporation of the bromine atom at $\mathrm{C} 6$ in a quinazolinone skeleton resulted in a significant increase in potency of isoxazolidine-conjugates 11b-11i toward both VZV (up to five-fold higher) and HCMV (up to three-fold higher) when compared with previously described analogous conjugates 10b-10i lacking a bromine substituent at $\mathrm{C} 6$ of the quinazolinone moiety. Moreover, inhibitory properties of the newly synthesized compounds $\mathbf{1 1 b} \mathbf{- 1 1 k}$ toward tested cell lines were also slightly higher than those of previously described analogues $\mathbf{1 0 b}-\mathbf{1 0 k}$.

Author Contributions: The research group from the Medical University of Lodz (D.G.P. and M.G.D.) conceived the research project, participated in all steps of the research, interpreted the results, discussed the experimental data, and prepared the manuscript. The research group from KU Leuven (G.A., D.S., and R.S.) conducted the biological assays and provided the experimental procedures and results. All authors read, commented on, and approved the manuscript.

Funding: This research was funded by the Medical University of Lodz (internal fund 503/3-014-01/503-31-001) and by the KU Leuven (GOA 15/19 TBA). 
Acknowledgments: The authors wish to express their gratitude to Leentje Persoons, Ellen De Waegenaere, Bianca Stals, Kirsten Lepaige, Niels Willems, and Nathalie Van Winkel for their excellent technical assistance.

Conflicts of Interest: The authors declare no conflict of interest.

\section{References}

1. König, B.; Grätzei, M.A. Novel Immunosensor for Herpes Viruses. Anal. Chem. 1994, 66, 341-344. [CrossRef] [PubMed]

2. Hollier, L.M.; Grissom, H. Human Herpes Viruses in Pregnancy: Cytomegalovirus, Epstein-Barr Virus, and Varicella Zoster Virus. Clin. Perinatol. 2005, 32, 671-696. [CrossRef] [PubMed]

3. Field, H.J.; Vere Hodge, R.A. Recent developments in anti-herpesvirus drugs. Br. Med. Bull. 2013, 106, 213-249. [CrossRef] [PubMed]

4. Cohen, J.I. Herpes Zoster. N. Engl. J. Med. 2013, 369, 255-263. [CrossRef] [PubMed]

5. De Clercq, E. Antivirals for the treatment of herpes virus infections. J. Antimicrob. Chemother. 1993, 32 (Suppl. A), 121-132. [CrossRef] [PubMed]

6. Ma, J.; Li, P.; Li, X.; Shi, Q.; Wan, Z.; Hu, D.; Jin, L.; Song, B. Synthesis and Antiviral Bioactivity of Novel 3-((2-((1E,4E)-3-Oxo-5-arylpenta-1,4-dien-1-yl)phenoxy)methyl)-4(3H)-quinazolinone Derivatives. J. Agric. Food Chem. 2014, 62, 8928-8934. [CrossRef] [PubMed]

7. Dohle, W.; Jourdan, F.L.; Menchon, G.; Prota, A.E.; Foster, P.A.; Mannion, P.; Hamel, E.; Thomas, M.P.; Kasprzyk, P.G.; Ferrandis, E.; et al. Quinazolinone-Based Anticancer Agents: Synthesis, Antiproliferative SAR, Antitubulin Activity, and Tubulin Co-crystal Structure. J. Med. Chem. 2018, 61, 1031-1044. [CrossRef] [PubMed]

8. Al-Suwaidan, I.A.; Abdel-Aziz, A.A.-M.; Shawer, T.Z.; Ayyad, R.R.; Alanazi, A.M.; El-Morsy, A.M.; Mohamed, M.A.; Abdel-Aziz, N.I.; El-Sayed, M.A.-A.; El-Azab, A.S. Synthesis, antitumor activity and molecular docking study of some novel 3-benzyl-4(3H)-quinazolinone analogues. J. Enzyme Inhib. Med. Chem. 2016, 31, 78-89. [CrossRef] [PubMed]

9. Zhang, J.; Liu, J.; Ma, Y.; Re, D.; Cheng, P.; Zhao, J.; Zhang, F.; Yao, Y. One-pot synthesis and antifungal activity against plant pathogens of quinazolinone derivatives containing an amide moiety. Bioorg. Med. Chem. Lett. 2016, 26, 2273-2277. [CrossRef] [PubMed]

10. Raju, G.N.; Sai, K.B.; Resshma, V.; Sudarshini, N.; Sowmya, P.L.; Nalini, Y.; Nadendla, R.R. Potential antimicrobial activities of quinazolinone derivatives. J. Chem. Pharm. Res. 2015, 7, 1279-1287.

11. Rakesh, K.P.; Ramesh, S.; Kumar, H.M.M.; Chandan, S.; Gowda, D.C. Quinazolinones linked amino acids derivatives as a new class of promising antimicrobial, antioxidant and anti-inflammatory agents. Eur. J. Chem. 2015, 6, 254-260. [CrossRef]

12. Kuneš, J.; Bažant, J.; Pour, M.; Waisser, K.; Šlosárek, M.; Janota, J. Quinazoline derivatives with antitubercular activity. Il Farmaco 2000, 55, 725-729. [CrossRef]

13. Pandit, U.; Dodiya, A. Synthesis and antitubercular activity of novel pyrazole-quinazolinone hybrid analogs. Med. Chem. Res. 2013, 22, 3364-3371. [CrossRef]

14. Kumar, A.; Bansal, D.; Bajaj, K.; Sharma, S.; Srivastava, V.K. Synthesis of some newer derivatives of 2-amino benzoic acid as potent anti-inflammatory and analgesic agents. Bioorg. Med. Chem. 2003, 11, 5281-5291. [CrossRef]

15. Noureldin, N.A.; Kothayer, H.; Lashine, E.-S.M.; Baraka, M.M.; El-Eraky, W.; El Awdan, S.A. Synthesis, Anticonvulsant Activity, and SAR Study of Novel 4-Quinazolinone Derivatives. Arch. Pharm. Chem. Life Sci. 2017, 350, e1600332. [CrossRef] [PubMed]

16. Mokale, S.N.; Palkar, A.D.; Dube, P.N.; Sakle, N.S.; Miniyar, P.B. Design, synthesis and in vivo screening of some novel quinazoline analogs as anti-hyperlipidemic and hypoglycemic agents. Bioorg. Med. Chem. Lett. 2015, 6, 272-276. [CrossRef] [PubMed]

17. Alafeefy, A.M.; Kadi, A.A.; Al-Deeb, O.A.; El-Tahir, K.E.H.; Al-Jaber, N.A. Synthesis, analgesic and anti-inflammatory evaluation of some novel quinazoline derivatives. Eur. J. Med. Chem. 2010, 45, 4947-4952. [CrossRef] [PubMed]

18. Nawrocka, W.; Zimecki, M. Syntheses of Novel 3-Amino-2(1H)-thioxo-4(3H)-quinazolinones and Evaluation of Their Immunotropic Activity. Part III. Arch. Pharm. Pharm. Med. Chem. 1997, 330, 399-405. [CrossRef] 
19. Selvam, P.; Murugesh, N.; Chandramohan, M.; Pannecouque, C.; De Clercq, E. Synthesis, Antiviral and Cytotoxic Activities of 2-(2-Phenyl carboxylic acid)-3-Phenylquinazolin-4(3H)-one Derivatives. Indian J. Pharm. Sci. 2010, 72, 806-809. [CrossRef] [PubMed]

20. Dinakaran, M.; Selvam, P.; De Clercq, E.; Sridhar, S.K. Synthesis, Antiviral and Cytotoxic Activity of 6-Bromo-2,3-disubstituted-4(3H)-quinazolinones. Biol. Pharm. Bull. 2003, 26, 1278-1282. [CrossRef] [PubMed]

21. Gao, X.; Cai, X.; Yan, K.; Song, B.; Gao, L.; Chen, Z. Synthesis and Antiviral Bioactivities of 2-Aryl- or 2-Methyl-3-(substituted-Benzalamino)-4(3H)-quinazolinone Derivatives. Molecules 2007, 12, 2621-2642. [CrossRef] [PubMed]

22. Abbas, S.Y.; El-Bayouki, K.A.M.; Basyouni, W.M.; Mostafa, E.A. New series of 4(3H)-quinazolinone derivatives: Syntheses and evaluation of antitumor and antiviral activities. Med. Chem. Res. 2018, 27, 571-582. [CrossRef]

23. Schroeder, C.E.; Yao, T.; Sotsky, J.; Smith, R.A.; Roy, S.; Chu, Y.-K.; Guo, H.; Tower, N.A.; Noah, J.W.; McKellip, S.; et al. Development of (E)-2-((1,4-Dimethylpiperazin-2-ylidene)amino)-5-nitro- $N$-phenylbenzamide, ML336: Novel 2-Amidinophenylbenzamides as Potent Inhibitors of Venezuelan Equine Encephalitis Virus. J. Med. Chem. 2014, 57, 8608-8621. [CrossRef] [PubMed]

24. Leivers, A.L.; Tallant, M.; Shotwell, J.B.; Dickerson, S.; Leivers, M.R.; McDonald, O.B.; Gobel, J.; Creech, K.L.; Strum, S.L.; Mathis, A.; et al. Discovery of Selective Small Molecule Type III Phosphatidylinositol 4-Kinase Alpha (PI4KIII $\alpha$ ) Inhibitors as Anti Hepatitis C (HCV) Agents. J. Med. Chem. 2014, 57, 2091-2106. [CrossRef] [PubMed]

25. Piotrowska, D.G.; Andrei, G.; Schols, D.; Snoeck, R.; Grabkowska-Drużyc, M. New Isoxazolidine-Conjugates of Quinazolinones-Synthesis, Antiviral and Cytostatic Activity. Molecules 2016, 21, 959. [CrossRef] [PubMed]

26. Piotrowska, D.G. N-Substituted C-diethoxyphosphorylated nitrones as useful synthons for the synthesis of $\alpha$-aminophosphonates. Tetrahedron Lett. 2006, 47, 5363-5366. [CrossRef]

27. Erb, B.; Akue, R.; Rigo, B. Synthesis of 2-Aminoquinazoline-4(3H)-one Derivatives as Potential Potassium Channel Openers. J. Heterocycl. Chem. 2000, 37, 253-260. [CrossRef]

28. Dolzhenko-Podchezertseva, A.V.; Korkodinova, L.M.; Vasilyuk, M.V.; Kotegov, V.P. Synthesis and antiinflamatory activity of $\mathrm{N}$-acyl-5-bromoanthranilic acid amides. Pharm. Chem. J. 2002, 36, 647-648. [CrossRef]

29. Witt, A.; Bergman, J. Synthesis and reactions of some 2-vinyl-3H-quinazolin-4-ones. Tetrahedron 2000, 56, 7245-7253. [CrossRef]

Sample Availability: Samples of the compounds are not available from the authors.

(C) 2018 by the authors. Licensee MDPI, Basel, Switzerland. This article is an open access article distributed under the terms and conditions of the Creative Commons Attribution (CC BY) license (http://creativecommons.org/licenses/by/4.0/). 